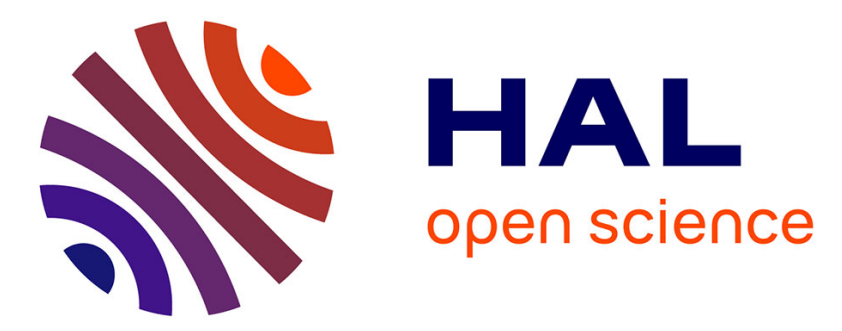

\title{
Using in-situ airborne measurements to evaluate three cloud phase products derived from CALIPSO
}

Gregory Cesana, H. Chepfer, D. Winker, B. Getzewich, X. Cai, O. Jourdan, G. Mioche, H. Okamoto, Y. Hagihara, V. Noel, et al.

\section{- To cite this version:}

Gregory Cesana, H. Chepfer, D. Winker, B. Getzewich, X. Cai, et al.. Using in-situ airborne measurements to evaluate three cloud phase products derived from CALIPSO. Journal of Geophysical Research: Atmospheres, 2016, 10.1002/2015JD024334 . hal-01318943

\section{HAL Id: hal-01318943 \\ https://hal.sorbonne-universite.fr/hal-01318943}

Submitted on 20 May 2016

HAL is a multi-disciplinary open access archive for the deposit and dissemination of scientific research documents, whether they are published or not. The documents may come from teaching and research institutions in France or abroad, or from public or private research centers.
L'archive ouverte pluridisciplinaire HAL, est destinée au dépôt et à la diffusion de documents scientifiques de niveau recherche, publiés ou non, émanant des établissements d'enseignement et de recherche français ou étrangers, des laboratoires publics ou privés. 


\section{Journal of Geophysical Research: Atmospheres}

\section{RESEARCH ARTICLE \\ 10.1002/2015JD024334 \\ Using in situ airborne measurements to evaluate three cloud phase products derived from CALIPSO}

Key Points:

- Comparison of the cloud and cloud phase of three CALIPSO climatologies with in situ measurements

- Cloud detection differences due to vertical/horizontal averaging and fully attenuated pixels

- Very high agreement for midlatitude ice clouds, more disagreement with the mixed-phase clouds

Supporting Information:

- Supporting Information S1

Correspondence to:

G. Cesana,

Gregory.v.cesana@jpl.nasa.gov

\section{Citation:}

Cesana, G., et al. (2016), Using in situ airborne measurements to evaluate three cloud phase products derived from CALIPSO, J. Geophys. Res. Atmos., 121, doi:10.1002/2015JD024334.

Received 10 OCT 2015 Accepted 30 MAR 2016 Accepted article online 6 APR 2016

\author{
G. Cesana ${ }^{1,2}$, H. Chepfer ${ }^{1}$, D. Winker ${ }^{3}$, B. Getzewich ${ }^{4}$, X. Cai ${ }^{4}$, O. Jourdan ${ }^{5}$, G. Mioche ${ }^{5}$, H. Okamoto ${ }^{6}$, \\ Y. Hagihara ${ }^{6}$, V. Noel $^{7}$, and M. Reverdy ${ }^{8}$ \\ ${ }^{1}$ Laboratoire de Météorologie Dynamique, Institut Pierre-Simon Laplace, Université Paris 6, Paris, France, ${ }^{2}$ Jet Propulsion \\ Laboratory, California Institute of Technology, Pasadena, California, USA, ${ }^{3}$ NASA Langley Research Center, Hampton, \\ Virginia, USA, ${ }^{4}$ SSAI, Hampton, Virginia, USA, ${ }^{5}$ Laboratoire de Météorologie Physique, Université Blaise Pascal, Clermont-Ferrand, \\ France, ${ }^{6}$ Research Institute for Applied Mechanics, Kyushu University, Fukuoka, Japan, ${ }^{7}$ Laboratoire d'Aérologie/CNRS, \\ Toulouse, France, ${ }^{8}$ Laboratoire de Météorologie Dynamique, Institut Pierre-Simon Laplace, CNRS, Palaiseau, France
}

Abstract We compare the cloud detection and cloud phase determination of three independent climatologies based on Cloud-Aerosol Lidar and Infrared Pathfinder Satellite Observation (CALIPSO) to airborne in situ measurements. Our analysis of the cloud detection shows that the differences between the satellite and in situ measurements mainly arise from three factors. First, averaging CALIPSO Level I data along track before cloud detection increases the estimate of high- and low-level cloud fractions. Second, the vertical averaging of Level 1 data before cloud detection tends to artificially increase the cloud vertical extent. Third, the differences in classification of fully attenuated pixels among the CALIPSO climatologies lead to differences in the low-level Arctic cloud fractions. In another section, we compare the cloudy pixels detected by colocated in situ and satellite observations to study the cloud phase determination. At midlatitudes, retrievals of homogeneous high ice clouds by CALIPSO data sets are very robust (more than $94.6 \%$ of agreement with in situ). In the Arctic, where the cloud phase vertical variability is larger within a $480 \mathrm{~m}$ pixel, all climatologies show disagreements with the in situ measurements and CALIPSO-General Circulation Models-Oriented Cloud Product (GOCCP) report significant undefined-phase clouds, which likely correspond to mixed-phase clouds. In all CALIPSO products, the phase determination is dominated by the cloud top phase. Finally, we use global statistics to demonstrate that main differences between the CALIPSO cloud phase products stem from the cloud detection (horizontal averaging, fully attenuated pixels) rather than the cloud phase determination procedures.

\section{Introduction}

Clouds cover most of the Earth (more than 70\% [Stubenrauch et al., 2013]) and are involved in many large-scale processes, which are still misunderstood (e.g., El Niño-Southern Oscillation, Madden-Julian Oscillation, North Atlantic Oscillation). The evolution of clouds and their radiative effects is still a major source of uncertainty and limits our understanding of climate change [Boucher et al., 2013]. The presence of clouds in the atmosphere modulates the exchanges of energy at the top of the atmosphere (TOA) as well as the surface. Although reliable measurements at TOA [e.g., Harrison et al., 1990; Wielicki et al., 1996; Kandel et al., 1998] allow monitoring the global energy balance precisely, surface radiation measurements are sparse and therefore more uncertain [e.g., Stephens et al., 2012; Ohmura et al., 1998]. Additional information about the vertical structure of clouds and their phase [Stephens et al., 2002; Winker et al., 2010] helps improve those surface estimates [Stephens et al., 2012].

Cloud phase transition viewed on a global scale must be better understood to progress on our understanding on the role of clouds on climate. The influence of the cloud phase on the climate system (e.g., climate sensitivity, albedo, and cloud fraction) has been demonstrated using general circulation models (GCMs) [e.g., $L i$ and Le Treut, 1992; Gregory and Morris, 1996; Kay et al., 2016]. Recent studies have shown that changing the phase description in a GCM could lead to biases not only on the radiative flux [Yun and Penner, 2012] but also in the zonal cloud fraction, the heating rate, the humidity, and the cloud water content [Cheng et al., 2012]. Those changes are even more important at middle and high latitudes, where mixed-phase clouds are ubiquitous [e.g., Forbes and Ahlgrimm, 2014]. Cloud phase is thus one of the sensitive parameters in GCMs that have to be constrained and evaluated to improve climate projections. For this purpose, global scale satellite observations have a spatial cover well suited for GCM evaluation (grid size typically larger than $100 \mathrm{~km}$ ) and have been used recently to emphasize models' flaws [Cesana et al., 2015; Komurcu et al., 2014]. 
Different methods have been developed to retrieve the cloud thermodynamic phase from passive sensor satellites. The most simple is to set a threshold on the cloud top temperature [Rossow and Schiffer, 1999; Guignard et al., 2012]. Another one-extensively used in visible, infrared and microwave radiometers and spectrometers-is based on both brightness temperatures and brightness temperature differences (BTD) [e.g., Platnick et al., 2003; Pavolonis et al., 2005; Stephens and Kumerrow, 2007]. However, thin cirrus, mixedphase, and supercooled liquid clouds remain often misclassified or challenging to classify. The use of cloud emissivity ratios [Parol et al., 1991] has been proven to slightly mitigate the deficiencies of the BTD-based method such as the misclassification of thin cirrus clouds [e.g., Heidinger and Pavolonis, 2009; Pavolonis, 2010]. Aside from the brightness temperature, liquid and ice particles may be discriminated depending on their shapes by using spaceborne polarization measurements of cloud tops [Goloub et al., 2000]. Moreover, some cloud phase retrievals may also be obtained using ambient temperature from reanalysis data [Uppala et al., 2005]. Yet the cloud phase and its transition between liquid and ice depend not only on the temperature but also on the water vapor pressure, the aerosol types present, and the shape, size, and number of the particles. Retrievals based on measurements from spaceborne passive instruments do not describe the entire profile but only the uppermost layers, integrated over a height that is moreover hard to quantify with less confidence over land. Besides, in satellite remote sensing, the cloud phase is often used to retrieve other variables. For example, assumptions regarding the size and shape of the cloud particlesnecessary to estimate the optical depth or the cloud water content-are often based on the retrieved cloud phase [Nasiri and Kahn, 2008; Rossow et al., 1991]. Errors in the retrieved cloud phase might cause biases in these quantities [Pavolonis and Key, 2003; Rossow and Schiffer, 1999]. Therefore, other spaceborne measurements - sensitive to thin cirrus, supercooled liquid, and mixed-phase clouds, reliable over land, and independent of the methods mentioned above-are necessary to improve our knowledge of the cloud phase.

The Cloud-Aerosol Lidar and Infrared Pathfinder Satellite Observations (CALIPSO) [Winker et al., 2010] satellite carries an active remote sensing instrument-i.e., the Cloud-Aerosol LIdar with Orthogonal Polarization (CALIOP). In contrast with passive instruments, it allows one to retrieve the vertically resolved cloud phase, for thin cirrus and supercooled liquid dense clouds, during daytime and nighttime and above all surfaces, thus providing significant new information compared to passive remote sensing-based cloud phase climatologies. For these reasons, the CALIPSO observations have been often used to validate cloud phase retrievals of spaceborne passive satellites, leading to a significant improvement of these retrievals [e.g., Baum et al., 2012; Kahn et al., 2014; Jin and Nasiri, 2014; Heidinger et al., 2010]. CALIOP's near-nadir pointing laser beam at $532 \mathrm{~nm}$ is linearly polarized. It measures total attenuated backscatter (ATB), which is split in two components: one parallel $\left(A T B_{\text {par }}\right)$ and one perpendicular $\left(A T B_{\text {perp }}\right)$ to the incident plane. $A$ nonzero perpendicular signal implies a change in the polarization state of the backscattered beam compared to the emitted beam. Unlike spherical particles, nonspherical particles modify the polarization state of the laser beam for a single scattering case. The change of polarization state of the backscatter laser beam has been used since the early 1970s to discriminate liquid from ice clouds in ground-based lidar data [Schotland et al., 1971] and continues to be widely used for that purpose [e.g., Naud et al., 2010; Noel et al., 2006]. However, in spaceborne lidar observations, the distance to the cloud is larger compared to ground-based lidar. For a similar field of view, the illuminated cloud volume is therefore larger, which increases the impact of multiple scattering on measurements and complicates the cloud phase determination. For that reason, further information (e.g., total and perpendicular attenuated backscatter, and lidar attenuation) is used to separate liquid clouds from ice clouds [e.g., Cesana and Chepfer, 2013; Hu et al., 2009; Yoshida et al., 2010].

In this paper, we used three CALIPSO cloud phase climatologies, all vertically resolved and using algorithms mainly independent of temperature: the GCM-Oriented CALIPSO Cloud Product, (CALIPSO-GOCCP) [Cesana and Chepfer, 2013], the CALIPSO Science Team product (CALIPSO-ST) [Hu et al., 2009], and the CALIPSO Kyushu University product (CALIPSO-KU) [Yoshida et al., 2010; Hirakata et al., 2014]. As the developments of these three products were guided by different scientific questions, the choices made in their algorithms, such as the method to detect clouds and to retrieve the cloud phase, and the vertical and horizontal averaging, are not identical and lead to different results. For example, in comparing CALIPSO-GOCCP and CALIPSO-ST, Chepfer et al. [2013] showed that variations in detection sensitivity with horizontal averaging could generate differences in zonal mean cloud profiles up to a factor of 2 (see high clouds in the tropics in their Figure 9). Although their methods are different, all use polarization and ATB to discriminate liquid clouds (spherical liquid droplets) from ice clouds (nonspherical ice crystals). 
The phase transition of water within clouds happens at very small spatial-temporal scales (a few microns [e.g., Rogers and $\mathrm{Yau}, 1989]$ ]). These are impossible to observe with spaceborne instruments. It is therefore necessary to compare those satellite products with other robust cloud phase measurements. Airborne in situ measurements, which are sampled directly inside clouds, are one way to validate satellite retrievals [e.g., Mioche et al., 2010]. Compared to satellite products, in situ measurements describe the cloud phase more accurately and with a better spatial-temporal scale. Nevertheless, in situ measurements performed during field campaigns [e.g., Jourdan et al., 2010; Gayet et al., 2002; Heymsfield and Hjelmfelt, 1984] are very localized and limited to specific time periods and regions, so they cannot provide a global view of cloud phase transitions.

The objective of this study is threefold: (i) to explain the differences among the CALIPSO cloud phase products, (ii) to suggest improvements in cloud phase retrieval for current and future spaceborne lidar missions, and (iii) to emphasize the need for in situ measurements to validate the satellite retrievals. In parallel, our evaluation of the CALIPSO cloud phase products will improve our knowledge of the cloud phase on a global scale. In section 2, we describe the three CALIPSO data sets, the in situ airborne measurements, and the comparison method. We examine the results of the comparison between CALIPSO and aircraft cloud detection and cloud phase in sections 3 and 4, respectively. In section 5, we summarize the results of the study.

\section{Data Sets and Method}

The information presented in Table 1 helps to understand the differences between the data sets, by summarizing the various resolutions and definitions used by the different cloud detection and cloud phase determination procedures.

First, the horizontal and vertical averaging applied to the lidar profiles before cloud detection differ from one product to another (e.g., $333 \mathrm{~m}$ versus $80 \mathrm{~km}$ horizontally). This is expected to generate significant cloud detection differences, as previously discussed in, e.g., Hagihara et al. [2010, 2014] and Chepfer et al. [2013]. Second, more interestingly, the definitions of the "Fully attenuated" pixels-i.e., when the lidar is blind because the laser is completely attenuated-are inconsistent among the products. Third, some classifications, like the "undefined" cloud detection, the "uncertain" phase, or the "mixed" phase are populated (with different definitions) in some products but do not exist in others. As a consequence of these factors, although the three CALIPSO data sets use the same Level 1B version 3 CALIOP data (total and perpendicular ATB profiles) as inputs, the science questions that drive each has led to different definitions and spatial resolutions in each algorithm, in turn, leading to differences in the cloud products.

It is the goal of this paper to determine how much and where the differences in the design/definition of the algorithms impact the total cloud fraction profiles as well as the liquid and ice cloud fraction profiles reported at global scale.

A more detailed description of the data sets is given in the following section.

\subsection{The GCM-Oriented CALIPSO Cloud Product (CALIPSO-GOCCP)}

CALIPSO-GOCCP [Chepfer et al., 2010, 2013] has been developed from CALIPSO measurements of attenuated backscatter, with the aim of evaluating the cloud representation in GCMs with the joint use of a lidar simulator [Chepfer et al., 2008]. Every $333 \mathrm{~m}$ spaced profile is used at a vertical resolution of $480 \mathrm{~m}$ to compute the scattering ratio (SR), which is the ratio of the total attenuated backscattered signal (ATB) to the molecular attenuated backscattered signal $\left(\right.$ ATB $_{\text {mol }}$, ATB in presence of molecules only). The SR characterizes the presence of particulate matters in the layer. A CALIPSO-GOCCP $480 \mathrm{~m}$ pixel is diagnosed as cloudy when its SR is higher than or equal to 5 and the difference between total and molecular ATB $(\triangle A T B)$ is higher or equal to $2.5 \times 10^{-3} \mathrm{~km}^{-1} \mathrm{sr}^{-1}$. In the high troposphere, this SR5 threshold may lead to the underestimation of thin subvisible cirrus clouds, which have an optical depth lower than 0.03 [Martins et al., 2011]. According to its SR value, a pixel can also be diagnosed as uncertain $(3 \leq \mathrm{SR}<5)$, clear $(0.01 \leq \mathrm{SR}<3)$, fully attenuated $(0.01<\mathrm{SR})$, or rejected (depending on the signal-to-noise ratio, SNR). Fully attenuated and rejected pixels are not included in the global statistics. However, fully attenuated pixels are accounted for in the cloud detection validation to address their impact. Here we use GOCCP v2.9 which, compared to v2.68 (as in Chepfer et al. [2013]), includes an updated computation of the normalization ratio $(R)$, used to reject noise-contaminated daytime profiles. $R$ is defined as the ratio of the ATB averaged over \pm 33 profiles to the Molecular Density 
Table 1. Overview of the Different Products ${ }^{a}$

\begin{tabular}{|c|c|c|c|c|}
\hline 1. & GOCCP & ST & $\mathrm{KU}$ & Airborne-NP \\
\hline 2. Vertical resolution & $480 \mathrm{~m}$ & $\begin{array}{l}30 \mathrm{~m} \text { and } 60 \mathrm{~m} \\
\text { reprojected at } 480 \mathrm{~m}\end{array}$ & $\begin{array}{l}30 \mathrm{~m} \text { and } 60 \mathrm{~m} \\
\text { reprojected at } 240 \mathrm{~m}\end{array}$ & a few $\mathrm{cm}$ \\
\hline \multirow[t]{2}{*}{$\begin{array}{l}\text { 3. Horizontal resolution } \\
\text { and averaging }\end{array}$} & $\begin{array}{c}333 \mathrm{~m}<8.2 \mathrm{~km} \text { and } \\
1 \mathrm{~km}>8.2 \mathrm{~km} ; \text { no } \\
\text { horizontal averaging }\end{array}$ & $\begin{array}{l}333 \mathrm{~m}<8.2 \mathrm{~km} \text { and } 1 \mathrm{~km}>8.2 \mathrm{~km} \\
\text { Variable: from } 333 \mathrm{~m} \text { to } 80 \mathrm{~km}\end{array}$ & $\begin{array}{c}333 \mathrm{~m}<8.2 \mathrm{~km} \text { and } \\
1 \mathrm{~km}>8.2 \mathrm{~km} \text {; Fixed } \\
\text { to } 1.1 \mathrm{~km}\end{array}$ & $\begin{array}{l}200 \text { m Mid-lat } 80 \text { m Arctic; } \\
\text { no horizontal averaging }\end{array}$ \\
\hline & \multicolumn{3}{|c|}{ 4. Cloud Detection } & \\
\hline 5. Reference & Chepfer et al. [2010, 2013] & Vaughan et al. [2009] & Hagihara et al., 2010; & $\begin{array}{l}\text { Gayet et al., } 2009 \\
\text { Mioche et al., } 2010\end{array}$ \\
\hline 6. Cloud & $\begin{array}{c}\text { SR5 and } \triangle \text { ATB }>2.5 \mathrm{e}^{-3} \\
\mathrm{~km}^{-1} \mathrm{sr}^{-1}\end{array}$ & $\begin{array}{l}\text { SR } 1.2 \text { to } 15 \\
\text { See Chepfer et al. [2013] }\end{array}$ & Okamoto et al. [2007, 2008] & $\begin{array}{l}\text { Extinction coefficient }>0.02 \mathrm{~km}^{-1} \\
\text { (midlatitude) }>0.05 \mathrm{~km}^{-1} \text { (arctic) }\end{array}$ \\
\hline 7. Clear & $0.01<\mathrm{SR}<1.2$ & $\begin{array}{l}\text { All what is not Cloudy } \\
\text { and not Fully attenuated }\end{array}$ & All what is not Cloudy & $\begin{array}{l}\text { Extinction coefficient }<0.02 \mathrm{~km}^{-1} \\
\quad \text { (mid-lat) }<0.05 \mathrm{~km}^{-1} \text { (Arctic) }\end{array}$ \\
\hline 8. Full attenuation & $\mathrm{SR}<0.01$ & $\begin{array}{l}\text { Detect surface echo } \\
\text { and slope of ATB }\end{array}$ & Classified as clear & - \\
\hline \multirow[t]{2}{*}{ 9. Uncert } & $1.2<\mathrm{SR}<5$ : usually aerosols & - & - & - \\
\hline & \multicolumn{3}{|c|}{ 10. Cloud Phase Determination } & \\
\hline 11. Reference & Cesana and Chepfer [2013] & Hu et al. [2010] & $\begin{array}{l}\text { Yoshida et al. [2010] } \\
\text { Hirakata et al. [2014] }\end{array}$ & $\begin{array}{l}\text { Gayet et al. [2002] } \\
\text { Jourdan et al. [2010] }\end{array}$ \\
\hline 12. Liquid & $\begin{array}{c}\mathrm{ATB}_{\text {perp }} \\
\mathrm{T}\end{array}$ & $\begin{array}{c}\delta=\mathrm{f}(\mathrm{ATB}) \\
\mathrm{T} \\
\mathrm{ATB}_{1064} \\
\mathrm{CR}\end{array}$ & $\begin{array}{l}\qquad \delta=\mathrm{f}(\chi) \\
\text { Spatial continuity test }\end{array}$ & $0.83<g<0.9$ \\
\hline 13. Ice & $\begin{array}{c}\mathrm{ATB}_{\text {perp }}=\mathrm{f}(\mathrm{ATB}) \\
T\end{array}$ & $\begin{array}{c}\delta=\mathrm{f}(\mathrm{ATB}) \\
T \\
\mathrm{ATB}_{1064} \\
\mathrm{CR}\end{array}$ & $\begin{array}{l}\qquad \delta=\mathrm{f}(\chi) \\
\text { Spatial continuity test }\end{array}$ & $0.7<g<0.8$ \\
\hline 14. Mixed & - & $\begin{array}{l}\text { Both liquid and ice are } \\
\text { detected at } \Delta z=30 \mathrm{~m} \\
\text { (or } 60 \mathrm{~m} \text { ) in the } \\
\text { same } 480 \mathrm{~m} \text { pixel }\end{array}$ & - & $\begin{array}{c}0.8<g<0.83 \text { Both liquid and ice } \\
\text { but dominated by liquid phase }\end{array}$ \\
\hline 15. Undefined & $\begin{array}{l}\text { Cloud below a cloud } \\
\text { with } \operatorname{SR}(z)>30\end{array}$ & - & $\begin{array}{l}\text { Either liquid droplets } \\
\text { or randomly oriented } \\
\text { ice crystals }\end{array}$ & - \\
\hline
\end{tabular}

\footnotetext{
${ }^{\mathrm{a}} \mathrm{SR}$, Scattering Ratio; ATB, Attenuated Total Backscatter; $\triangle \mathrm{ATB}=\mathrm{ATB}-\mathrm{ATB}_{\text {mol }}$ T, Temperature; $\left.\chi_{(\mathrm{i})}=\log _{10}\left[\mathrm{ATB}_{(\mathrm{i})} / \mathrm{ATB}_{(\mathrm{i}+1)}\right]\right) ;$ Depolarization Ratio $\delta=\mathrm{ATB}_{\text {perp }} / \mathrm{ATB}_{\text {par }}$ and the Color Ratio, $\mathrm{CR}=\mathrm{ATB}_{1064} / \mathrm{ATB}$.
}

(MD) number averaged over \pm 33 profiles between $20 \mathrm{~km}$ and $25 \mathrm{~km}$ during daytime [see Chepfer et al., 2010, section 2.1]. In v2.9, R is computed between 20 and $28 \mathrm{~km}$ during daytime, except during Polar Stratospheric Cloud (PSC) season over Antarctica (June through October [Noel et al., 2008]) and over the Arctic (December through February [Pitts et al., 2011]), where $R$ is computed between $28.5 \mathrm{~km}$ and $35 \mathrm{~km}$. Profiles with values of $R$ larger than $1.8 \times 10^{-31}$ ( $R_{\max }$ in $\mathrm{sr}^{-1} \mathrm{~mol}^{-1} \mathrm{~m}^{2}$, basically 3 times its mean over 3 months of data) or lower than $0.15 \times 10^{-31}\left(R_{\min }\right.$ in $\left.\mathrm{sr}^{-1} \mathrm{~mol}^{-1} \mathrm{~m}^{2}\right)$ are first rejected. Then, $R$ is calculated again using \pm 65 profiles. If the new $R$ value is between $R_{\min }$ and $R_{\max }$ the profile is not rejected. This reduces the number of daytimerejected profiles (from $36.2 \%$ to $4.3 \%$ for January-March 2007) while ensuring a good SNR.

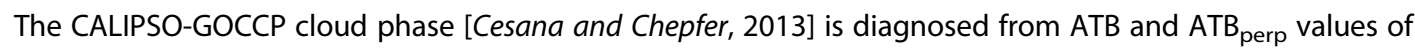
cloudy pixels. $\mathrm{ATB}_{\text {perp }}$ characterizes the change of polarization state of the laser beam. For spherical particles $\mathrm{ATB}_{\text {perp }}$ remains low and increases for nonspherical particles. Splitting the ATB and ATB perp 2-D distributions (using a discrimination threshold) allows distinguishing ice cloudy pixels from liquid cloudy pixels. However, because of lidar attenuation and signal noise, some pixels are classified as undefined (about 10\% of the cloudy pixels out of 3 months of global statistics [Cesana and Chepfer, 2013]). In less than 1\% of the cloudy pixels, the algorithm uses temperature to impose that clouds colder than $-42^{\circ} \mathrm{C}$ are ice and clouds warmer than $0^{\circ} \mathrm{C}$ are liquid. This helps reduce misclassifications. Temperature profiles come from the Goddard Earth 
Observing System Data Assimilation System Version 5 data assimilation product (GEOS5-DAS) [Rienecker et al., 2008], which are included in the Level 1 CALIPSO files. Those temperatures have been shown to be within the range of $\pm 1 \mathrm{~K}$ compared to observations for pressure between $1000 \mathrm{hPa}$ and $10 \mathrm{hPa}$ [Rienecker et al., 2011] and will be compared to the in situ temperatures later on (section 5.3 and Table S1 in the supporting information).

\subsection{CALIPSO Science Team (CALIPSO-ST) Cloud Product}

The CALIPSO-ST cloud product [Winker et al., 2010] is based on the NASA cloud mask (version 3 of the level 2 product). The CALIPSO-ST aims to document clouds with the best possible spatial-temporal resolution, taking advantage of the full capabilities of the CALIOP lidar. For this purpose, the cloud detection is done by the Selective Iterated BoundarY Location (SIBYL) algorithm [Vaughan et al., 2009] at the nominal vertical resolution ( $60 \mathrm{~m}$ from $8.2 \mathrm{~km}$ to $20.2 \mathrm{~km}, 30 \mathrm{~m}$ below) using SR detection thresholds adapted to scene brightness (typically $\mathrm{SR}=1.2$ to $\mathrm{SR}=15$ depending on the $\mathrm{SNR})$ and the horizontal averaging $(1 / 3,1,5,20$, and $80 \mathrm{~km})$. These detections at multiple scales are merged and accounted at specific along-track horizontal resolutions. Increasing the horizontal averaging allows for the detection of the optically thinnest clouds (e.g., subvisible cirrus cloud [Martins et al., 2011]) by increasing the SNR although it might also lead to overestimate of the cloud fraction in thin cirrus broken clouds (as suggested in Chepfer et al. [2013] and Hagihara et al. [2014], and as shown by Protat et al. [2014]). Full attenuation of the lidar signal in a thick cloud is detected from a lack of surface echo and the slope of the lidar signal. Those pixels are excluded from the global statistics but accounted for in the upcoming cloud detection validation against the in situ measurements, as with CALIPSO-GOCCP (section 2.1).

The CALIPSO-ST cloud phase [Hu et al., 2009] can be liquid, ice, or oriented ice crystals, based on a relationship between the layer-integrated depolarization ratio at $532 \mathrm{~nm} \delta$ (defined as $\delta=\mathrm{ATB}_{\text {perp }} / \mathrm{ATB}_{\text {par }}$ ) and the layerintegrated attenuated backscattered coefficient $\left(A T B=A T B_{\text {perp }}+A T B_{\text {par }}\right.$ ). Other criteria such as the temperature (GEOS5-DAS), the ATB at $1064 \mathrm{~nm}\left(\mathrm{ATB}_{1064}\right)$, or the color ratio $C R$ (defined as $C R=\mathrm{ATB}_{1064} / \mathrm{ATB}$ ), are also used to resolve ambiguities. Temperature is only used as a criterion for clouds below $-40^{\circ} \mathrm{C}$ or above $0^{\circ} \mathrm{C}$. However, $7.8 \%$ of $333 \mathrm{~m}$ detected pixels and $14.7 \%$ of $5 \mathrm{~km}$ detected pixels remain diagnosed as unknown phase for 1 year of global data for ambiguous pixels at temperature between $-40^{\circ} \mathrm{C}$ and $0^{\circ} \mathrm{C}$. Since phase is based on layer-integrated values, it is vertically homogeneous within a determined cloud layer. CALIPSOST data have been vertically averaged onto $480 \mathrm{~m}$ levels to facilitate the comparison with CALIPSO-GOCCP.

\subsection{CALIPSO Kyushu University (CALIPSO-KU) Cloud Product}

The CALIPSO-KU cloud particle type product [Yoshida et al., 2010; Hirakata et al., 2014] is based on the cloud mask using a combined CloudSat [Stephens et al., 2002] and CALIPSO-merged data set [Hagihara et al., 2010]. The aim of the KU cloud particle type is to document cloud particle phase and orientation. The product is also designed as inputs for the retrieval of cloud microphysics [Okamoto et al., 2010; Sato and Okamoto, 2011] and to validate the cloud representation in models.

The characteristics of the KU cloud mask are as follows: it takes into account the remaining noise signals after onboard subtraction of the background signal to reduce the effect of noise during daytime and reports the results at a fixed horizontal scale of $1.1 \mathrm{~km}$ for a better comparison with model outputs. The cloud mask determination is divided into two steps, i.e., threshold test for the ATB at $532 \mathrm{~nm}$ at the original vertical and horizontal resolutions to detect small water clouds and a spatial continuity test. This method was originally developed and tested for shipborne cloud radar and lidar observations at midlatitudes by Okamoto et al. [2007] and in the tropics by Okamoto et al. [2008]. After the cloud mask is determined, ATB and ATB perp are averaged, using the values for the original resolutions vertically over $240 \mathrm{~m}$ and horizontally over $1.1 \mathrm{~km}$. To avoid spurious signals caused by noise, when the average mask value exceeds 0.5 , the pixels are considered to be cloudy. Unlike in the CALIPSO-GOCCP and CALIPSO-ST approaches, fully attenuated pixels are counted as clear sky pixels, which may lead to underestimation of the cloud fraction. As mentioned in Hagihara et al. [2010, section 4.1], KU group examined the zonal mean cloud fraction difference between original CloudSatCALIPSO-KU product and modified CloudSat-CALIPSO-KU, in which attenuated bins were excluded in the September-November 2006 period. They considered that the bins only detected by CloudSat below the cloud tops detected by the CALIPSO as being attenuated and found a difference as small as $\sim 2 \%$ over the whole area (not shown). Therefore, the KU group considers that the underestimation related to fully attenuated pixels does not have a large impact on their product. 
The cloud phase or particle-type classification scheme is then carried out at the averaged resolution, i.e., $240 \mathrm{~m}$ in vertical and $1.1 \mathrm{~km}$ in horizontal. The algorithm relies on two-dimensional frequency diagram in terms of the ratio of ATB of two successive layers as a proxy of attenuation (defined as $x_{(i)}=\log _{10}\left[\operatorname{ATB}_{(i)} / \operatorname{ATB}_{(i+1)}\right]$ ) and $\delta$. Generally, ice particles show smaller attenuation than water, ice particles with randomly oriented ice show large $\delta$ with small attenuation, and horizontally oriented ice particles show small $\delta$ with small attenuation [Okamoto et al., 2010]. Water clouds can also have large $\delta$ due to multiple scattering so that large $\delta$ with larger attenuation assigns water clouds [Yoshida et al., 2010]. After the initial discrimination is examined, a "spatial consistency test" is considered and major type is determined. It uniquely provides a vertically resolved cloud particle type [Yoshida et al., 2010; Hirakata et al., 2014]. The phase of a $240 \mathrm{~m}$ cloudy pixel can be diagnosed as liquid (warm or supercooled), ice (randomly oriented or horizontally oriented ice or their mixture), unknown 1 (warm water or randomly oriented ice), and unknown 2 (missing $x$ ).

\subsection{Polar Nephelometer}

In this paper, we compare the three CALIPSO data sets with Polar Nephelometer (PN) measurements collected during two airborne field campaigns colocated (in time and space) with CALIPSO: the "Cirrus Cloud Experiment" (CIRCLE-2) [Eichler et al., 2009], and the "Arctic Study of Tropospheric Aerosol Clouds and Radiation" campaign (ASTAR) [Engvall et al., 2008]. The PN in situ probe [Gayet et al., 1997]-designed at the Laboratoire de Météorologie Physique (LaMP)—-measures directly the angular scattering coefficient at a wavelength of $0.8 \mu \mathrm{m}$ (nonnormalized scattering phase function) of an ensemble of cloud particles. From these measurements, some optical parameters can be retrieved such as the extinction coefficient, which characterizes the presence of particulate matter and the asymmetry parameter, which is a proxy of the particle shape [Jourdan et al., 2010]. We diagnose PN measurements (hereafter called pixels) as cloudy when the in situ extinction coefficient is higher than $0.05 \mathrm{~km}^{-1}$ for the Arctic flights [Gayet et al., 2009] and higher than $0.02 \mathrm{~km}^{-1}$ for the midlatitude flights [Mioche et al., 2010]. Other cases are diagnosed clear.

The cloud phase is retrieved based on the asymmetry factor measurements $(g)$ : between 0.83 and 0.9 , the cloud is considered to be dominated by the liquid phase; between 0.7 and 0.8 , the cloud is considered to be dominated by the ice phase; between 0.8 and 0.83 , the cloud contains either liquid droplets and ice crystals referred as mixed-phase but remains dominated by liquid droplets [Gayet et al., 2002; Jourdan et al., 2010]. The horizontal sampling of the CIRCLE-2 and ASTAR campaign measurements are approximately $200 \mathrm{~m}$ and $80 \mathrm{~m}$, respectively, depending on the aircraft speed.

For the sake of simplicity and to make reading easier, in the rest of the paper we will refer to CALIPSO-GOCCP, CALIPSO-ST, and CALIPSO-KU as GOCCP, ST, and KU.

\subsection{Validation Method}

The cloud phase comparison between all data sets may be biased by the cloud detection, i.e., differences in total cloud occurrence frequency irrespective of cloud phase. For example, let us assume the aircraft probe measures three successive ice clouds, one CALIPSO product detects three ice clouds and another CALIPSO product detects one ice cloud and two clear sky points. In terms of ice cloud frequency, the result is $100 \%$ agreement for the first product against 33\% for the second. However, in terms of cloud phase determination, either product correctly detects the ice phase in agreement with the aircraft measurements. Yet only one product is sensitive enough to detect all clouds while the other has cloud detection issues. This cloud detection issue put aside, both products diagnose the correct phase when a cloud is detected. Hence, the cloud phase agreement should be $100 \%$ for both. For this reason, we treated separately the cloud detection (section 3) from the cloud phase determination (section 4). First, we computed cloud detection statistics, and then, we computed cloud phase determination statistics only for clouds that were detected by all CALIPSO products in order to focus on the cloud phase determination ability of the three algorithms.

To compute agreement statistics between aircraft in situ measurements and satellite observations of the cloud phase, we selected five flights considering (i) the spatial-temporal colocalization between the aircraft and the satellite and (ii) the presence of clouds during the flights. We selected the flights that were closest to the CALIPSO tracks, \pm 10 min around the CALIPSO overpass time (Figure S1), to ensure the climatological conditions would remain similar. Yet this does not guarantee a perfect colocalization in time, and characteristics of the cloud (cloud top height, presence of cloud, and liquid/ice partition) might slightly change during the aircraft sampling. Consecutive airborne measurements are closer $(80 \mathrm{~m}$ and $200 \mathrm{~m})$ than successive 


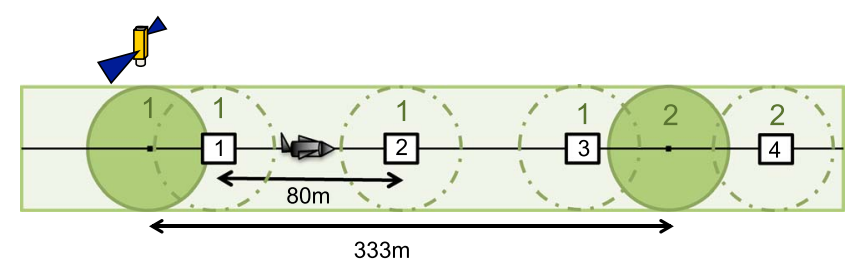

Figure 1. Schematic of the satellite oversampling consistent with the aircraft sampling. Aircraft measurements are represented by black numbered squares as opposed to green numbered circles for the satellite. The first CALIPSO measurement (green solid circle, on the left) is assumed to be continuous until the next measurement (green solid circle, on the right). The former measurement is oversampled (green dotted circles) to match the aircraft sampling 1,2 and 3 (black squares). in both data sets, we assessed the cloud phase determination. Rejected satellite pixels were excluded from all statistics. Details of the computation are available in the supporting information Text S1 for cloud detection and Text $\mathrm{S} 2$ for cloud phase determination.

\section{Cloud Detection Validation}

Cloud detection statistics with respect to the aircraft measurements for each CALIPSO product are presented in Table 2a for midlatitudes and Table $2 \mathrm{~b}$ for the Arctic. They are separated in two categories. The agreement fractions ( $F_{\text {agree, }}$ rows $\left.1-3\right)$ describe when the aircraft probe and the satellite both detect a cloud $\left(F_{\text {Acloud/ }}\right.$ Ccloud $)$ or clear sky ( $\left.F_{\text {Aclear/Cclear }}\right)$. The other fractions $\left(F_{\text {other, }}\right.$ rows $\left.4-10\right)$ describe when the aircraft probe and the satellite detect different features: opposite features $\left(F_{\text {Aclear/Ccloud, }}, F_{\text {Acloud/Cclear }}\right)$, uncertain features $\left(F_{\text {Aclear/Cuncert }}, F_{\text {Acloud/Cuncert }}\right)$, concerning only GOCCP in the selected flights, and attenuated features $\left(F_{\text {Aclear/Catt }}, F_{\text {Acloud/Catt }}\right)$, concerning GOCCP and ST. Uncertain fraction is small (at most $4.3 \%$ at midlatitudes and $3.8 \%$ in the Arctic) and represents aerosols and features optically too thin to be classified as cloud by GOCCP (see Chepfer et al. [2010, 2013] for more details). Although the attenuated features are small in GOCCP as well, they represent a significant part of the ST pixels, particularly in the Arctic (up to 27.8\%). The sum of the two categories (and of their subcategories) is $100 \%$. As the three algorithms do not use the same vertical resolution, horizontal averaging and the same fully attenuated pixel treatment (Table 1, rows 2,3 , and 8), it is therefore possible to evaluate the impact of each of those on the cloud detection when they are all compared to the same aircraft PN measurements.

Table 2a. Statistics of Cloud Detection (\%) Between CALIPSO Products (GOCCP, ST, KU) and the Colocated Aircraft Measurements for Three Flights at Midlatitudes ${ }^{\mathrm{a}}$ Midlatitudes

\begin{tabular}{|c|c|c|c|c|c|c|c|c|c|c|}
\hline \multirow{2}{*}{$\frac{\text { Day }}{\text { Product }}$} & \multicolumn{3}{|c|}{$2007 / 5 / 16$} & \multicolumn{3}{|c|}{$2007 / 5 / 25$} & \multicolumn{3}{|c|}{$2007 / 5 / 26$} & \multirow[b]{2}{*}{ Comments } \\
\hline & GOCCP & ST & $\mathrm{KU}$ & GOCCP & ST & $\mathrm{KU}$ & GOCCP & ST & $\mathrm{KU}$ & \\
\hline$F_{\text {agree }}(\%)$ & 95.8 & 89.6 & 97.6 & 87.3 & 76.4 & 84.5 & 80.9 & 81.2 & 84.1 & Agreement $^{\mathrm{b}}$ (see Figure 2) \\
\hline$F_{\text {Acloud/Ccloud }}$ & 85.9 & 84.6 & 84.1 & 38.2 & 47.3 & 23.4 & 62.7 & 77.7 & 63.4 & \\
\hline$F_{\text {Aclear/Cclear }}$ & 9.9 & 5 & 13.5 & 49.1 & 29.1 & 61.1 & 18.2 & 3.5 & 20.7 & \\
\hline$F_{\text {other }}(\%)$ & 4.2 & 10.4 & 2.4 & 12.7 & 23.6 & 15.5 & 19.1 & 18.8 & 15.9 & ST coarse horizontal resolution ${ }^{c}$ \\
\hline$F_{\text {Aclear/Ccloud }}$ & 4.2 & 10.4 & 1.7 & 2.5 & 23.6 & 0.9 & 1.9 & 18.8 & 1.8 & Vertical resolution differences ${ }^{d}$ \\
\hline$F_{\text {Aclear/Cuncert }}$ & 0 & 0 & 0 & 0 & 0 & 0 & 1.5 & 0 & 0 & \\
\hline$F_{\text {Aclear/Catt }}$ & 0 & 0 & 0 & 1.7 & 0 & 0 & 1.3 & 0 & 0 & \\
\hline$F_{\text {Acloud/Cclear }}$ & 0 & 0 & 0.7 & 8.5 & 0 & 14.6 & 10.1 & 0 & 14.1 & \\
\hline$F_{\text {Acloud/Cuncert }}$ & 0 & 0 & 0 & 0 & 0 & 0 & 4.3 & 0 & 0 & \\
\hline$F_{\text {Acloud/Catt }}$ & 0 & 0 & 0 & 0 & 0 & 0 & 0 & 0 & 0 & \\
\hline
\end{tabular}

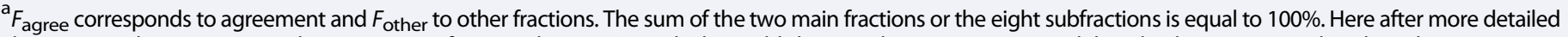
explanations in the comments column; Days are formatted as year/month/day. Bold data are the main category, while italic data correspond to the subcategory.

${ }^{b}$ All the data sets agree very well with the aircraft measurements at midlatitudes (section 3, second paragraph and see also Figure 2).

'Disagreements related to the high horizontal averaging of lidar profiles in ST (section 3.1 and Table 1, row 3).

${ }^{d}$ Disagreements related to the vertical resolution differences (section 3.2 and Table 1, row 2). 


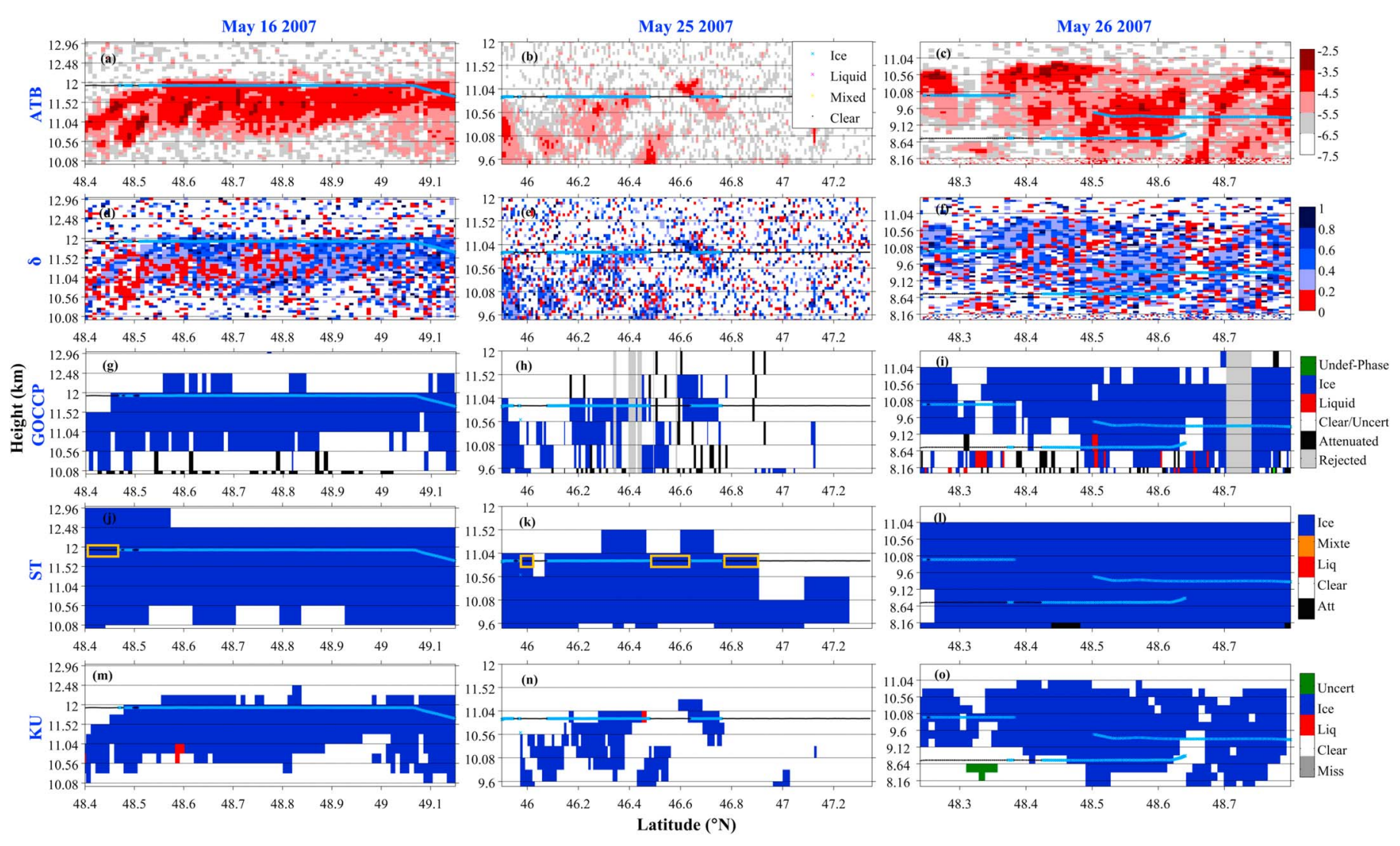

Figure 2. CALIPSO Level 1 Attenuated Total Backscattered signal (ATB; $\mathrm{km}^{-1} \mathrm{sr}^{-1}$; top row), CALIPSO Level 1 depolarization ratio $(\delta$; second row) and cloud phase mask profiles ( $x$ axis, ${ }^{\circ} \mathrm{N}$; $y$ axis, $\mathrm{km}$ ) of CALIPSO products (GOCCP, ST, KU) and the colocated aircraft cloud phase measurements (CIRCLE-2; colored crosses and black dots) at midlatitudes, for ( $a, d, g, j, m) 16$ May, (b, e, h, k, n) 25 May, and (c, f, i, l, o) 26 May, during 2007. The vertical resolution of GOCCP and ST is $480 \mathrm{~m}$ and $240 \mathrm{~m}$ for KU. Refer to the color bar directly in the figure for the different cloud mask definitions of CALIPSO products. The colored crosses (blue, magenta, yellow) correspond to ice/liquid/mixed-phase clouds measured by the aircraft, whereas the black dots correspond to clear sky. The coordinates in time and space correspond to those (last three rows) of Figure S1. Yellow rectangles delimitate the cloud fraction disagreements between ST and the aircraft measurements due to horizontal averaging (cf. section 3.1).

At midlatitudes, the three CALIPSO products and the aircraft measurements have high agreement fraction (76.4\% $<F_{\text {agree }}<97.6 \%$, Table 2a). These flights have been performed at altitudes between 8.5 and $12 \mathrm{~km}$, where clouds are generally composed of ice crystals. Their small optical thickness (typically $<3$ ) lets the CALIOP lidar detect multiple layers in the same profile without being totally attenuated. On the contrary, for the low-level dense clouds in the Arctic flights, the agreement fraction is significantly lower $(26 \%<$ $\left.F_{\text {agree }}<69.9 \%\right)$. The main reason for the disagreements between the lidar and the airborne PN is the strong attenuation of the laser beam caused primarily by the cloud portions where liquid droplets prevail (i.e., dominate the optical properties of the measured signal). Horizontal and vertical averaging are mostly responsible for the remaining disagreements as will be described in the following sections.

\subsection{Horizontal Averaging}

The three CALIPSO products use different horizontal averaging intervals (Table 1, row 3). Chepfer et al. [2013] showed that this, as well as the variable detection thresholds used by ST, could explain the significant differences in the cloud fraction (and to a lesser degree the cloud cover) between GOCCP and ST.

The vertical distribution of the CALIPSO ATB, depolarization ratio and the CALIPSO cloud phase mask products appear together with the aircraft cloud phase mask in Figure 2 for the midlatitude cases and in Figure 3 for the Arctic cases. For the midlatitude cases, ST reports more clouds than is measured by the

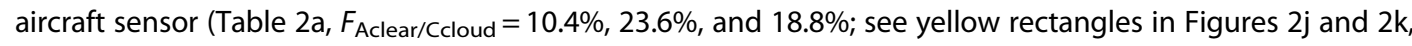
because the ST algorithm uses large horizontal averaging $(5,20$, and $80 \mathrm{~km}$ ) here. This difference is less 


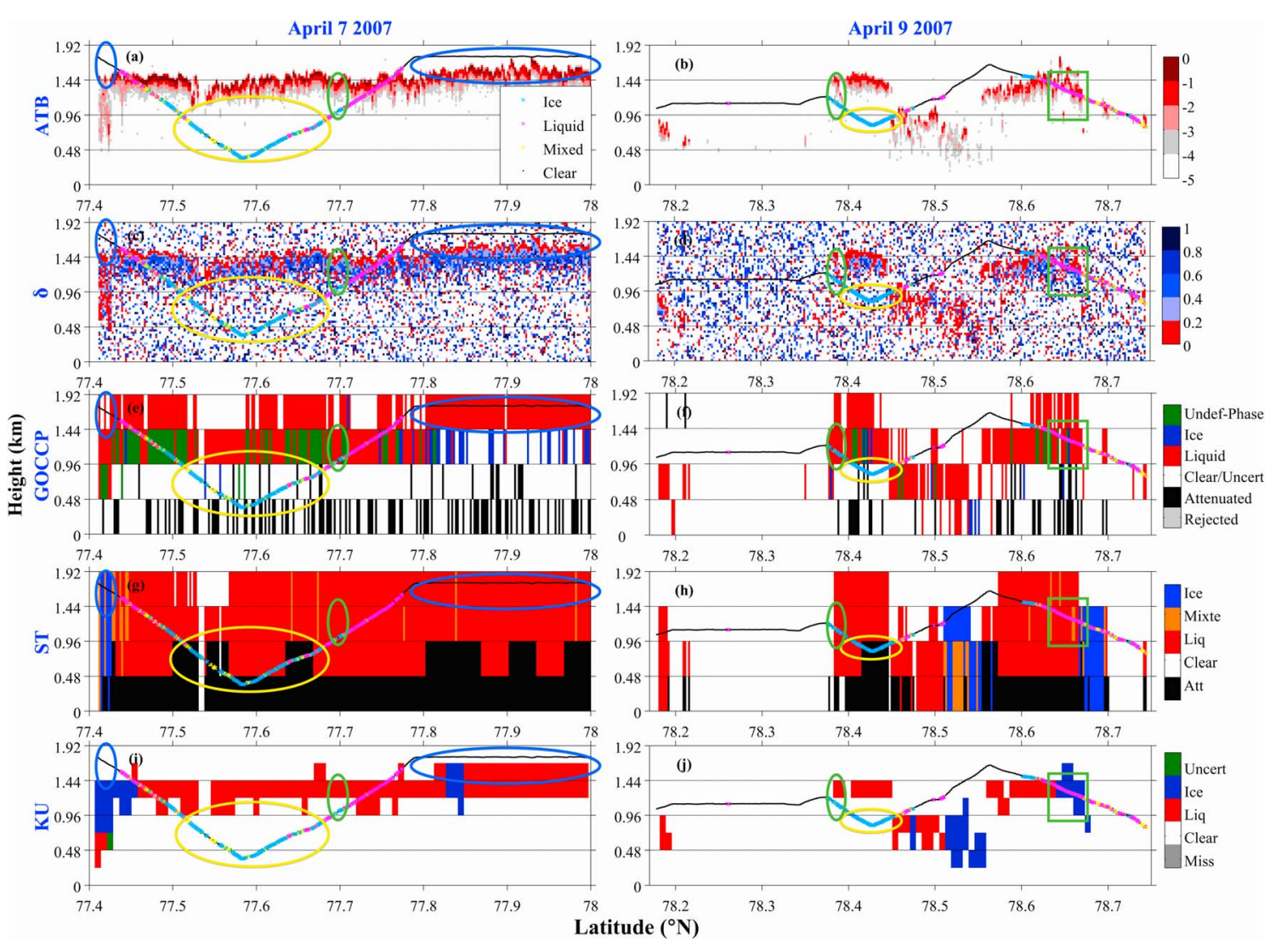

Figure 3. CALIPSO Level 1 Attenuated Total Backscattered signal (ATB; $\mathrm{km}^{-1} \mathrm{sr}^{-1}$; top row), CALIPSO Level 1 depolarization ratio $(\delta$; second row) and cloud phase mask of CALIPSO products (GOCCP, ST, KU) and the colocated aircraft cloud phase measurements (ASTAR; colored crosses and black dots) in Arctic, for (a, c, e, $g$, i) 7 April and (b, d, f, h, l) 9 April, during 2007. The vertical resolution of GOCCP and ST is $480 \mathrm{~m}$ and $240 \mathrm{~m}$ for KU. Refer to the color bar directly in the figure for the different cloud mask definitions of CALIPSO products. The colored crosses (blue, magenta, yellow) correspond to ice/liquid/mixed-phase clouds measured by the aircraft, whereas the black dots correspond to clear sky. The coordinates in time and space correspond to those (first two rows) of Figure S1. Yellow circles indicate the disagreement in cloud detection is due to the lidar attenuation (cf. section 3.3). Green circles highlight the cloud phase disagreements because of the attenuation and vertical resolution combined effect (cf. section 4.2.i). Green rectangles show noisy area where the cloud phase retrieval is ambiguous (cf. section 4.2.iii). Blue circles denote the disagreements between in situ airborne measurements and satellite data due to horizontal resolution (cf. section 3.1 ).

significant for GOCCP $(4.2 \%, 2.5 \%$, and $1.9 \%)$ and $\mathrm{KU}(1.7 \%, 0.9 \%$, and $1.8 \%)$, which do not average horizontally and use the original horizontal resolution ( $1 \mathrm{~km}$ between $8.2 \mathrm{~km}$ and $20.2 \mathrm{~km}$ ). Therefore, we found that, although the use of large horizontal averaging increases the cloud detection sensitivity, it may artificially enlarge the horizontal extent of clouds, consistent with the findings of Chepfer et al. [2013] and Hagihara et al. [2010, 2014]. The multiresolution feature of the ST retrieval is designed to minimize this effect [Vaughan et al., 2009].

\subsection{Vertical Resolution}

Although the vertical resolution of the CALIPSO products used in this paper is about a few hundred meters (Table 1, row 2: $480 \mathrm{~m}$ for GOCCP and ST, $240 \mathrm{~m}$ for KU), the full resolution of the lidar is finer ( $30 \mathrm{~m}$ below $8.2 \mathrm{~km}$ and $60 \mathrm{~m}$ above). Thus, some part of the $480 \mathrm{~m}$ or $240 \mathrm{~m}$ pixel might be clear, whereas the whole pixel is diagnosed as cloudy, and vice versa. As the aircraft vertical resolution is only a few centimeters, it is possible that the aircraft flies into clear parts of a CALIPSO cloudy-diagnosed pixel (the most frequent cases) or the cloudy parts of a CALIPSO clear-diagnosed pixel, leading to disagreements between the two retrievals. For example, Figure 3 shows the full resolution CALIPSO ATB (Figures $3 a$ and $3 b$ ) and all CALIPSO cloud masks (Figures $3 \mathrm{e}-3 \mathrm{j}$ ) along the CALIPSO track together with the flight path, for the Arctic cases. Near $77.42^{\circ} \mathrm{N}$ (blue circles), GOCCP and ST diagnose several consecutive cloudy pixels between $1.44 \mathrm{~km}$ and $1.92 \mathrm{~km}$. A visual inspection of the full resolution CALIPSO ATB observations suggests that the actual cloud top layer is located near $1.5 \mathrm{~km}$. However, the features located between $1.44 \mathrm{~km}$ and approximately $1.5 \mathrm{~km}$ are optically thick enough to be diagnosed as cloudy by the GOCCP and ST mask in the pixels between $1.44 \mathrm{~km}$ and $1.92 \mathrm{~km}$. 
Table 2b. Statistics of Cloud Detection (\%) Between CALIPSO Products (GOCCP, ST, KU) and the Colocated Aircraft Measurements for Two Flights in the Arctic $^{a}$

\begin{tabular}{|c|c|c|c|c|c|c|c|}
\hline \multicolumn{7}{|c|}{ Arctic } & \multirow[b]{3}{*}{ Comments } \\
\hline \multirow{2}{*}{$\begin{array}{l}\text { Day } \\
\text { Product }\end{array}$} & \multicolumn{3}{|c|}{$2007 / 4 / 7$} & \multicolumn{3}{|c|}{$2007 / 4 / 9$} & \\
\hline & GOCCP & ST & $\mathrm{KU}$ & GOCCP & ST & $\mathrm{KU}$ & \\
\hline$F_{\text {agree }}(\%)$ & 30.6 & 26 & 59.4 & 69.9 & 67.5 & 65.1 & \\
\hline$F_{\text {Acloud/Ccloud }}$ & 26 & 25.8 & 14.8 & 19.3 & 25.3 & 10.2 & \\
\hline$F_{\text {Aclear/Cclear }}$ & 4.6 & 0.2 & 44.6 & 50.6 & 42.2 & 54.9 & \\
\hline$F_{\text {other }}(\%)$ & 69.4 & 74 & 40.6 & 30.1 & 32.7 & 34.9 & \\
\hline$F_{\text {Aclear/Ccloud }}$ & 38.5 & 43.2 & 0.5 & 3.1 & 12.8 & 0 & Vertical resolution differences ${ }^{b}$ \\
\hline$F_{\text {Aclear/Cuncert }}$ & 1.9 & 0 & 0 & 1.3 & 0 & 0 & Definition of uncert in GOCCP \\
\hline$F_{\text {Aclear/Catt }}$ & 0 & 1.6 & 0 & 0 & 0 & 0 & \\
\hline$F_{\text {Acloud/Cclear }}$ & 21.8 & 1.4 & 40.1 & 20.7 & 11.7 & 34.9 & Lidar attenuation $^{\mathrm{d}}$ \\
\hline$F_{\text {Acloud/Cuncert }}$ & 2.6 & 0 & 0 & 3.8 & 0 & 0 & \\
\hline$F_{\text {Acloud/Catt }}$ & 4.6 & 27.8 & 0 & 1.2 & 8.2 & 0 & Lidar attenuation $^{d}$ \\
\hline
\end{tabular}

${ }^{\mathrm{a}} F_{\text {agree }}$ corresponds to agreement and and $F_{\text {other }}$ to other fractions. The sum of the two main fractions or the eight subfractions is equal to $100 \%$. Here after more detailed explanations in the comments column; Days are formatted as year/month/day. Bold data are the main category, while italic data correspond to the subcategory.

${ }^{\mathrm{b}}$ Disagreements related to the vertical resolution differences (section 3.2 and Table 1, row 2).

CUncertainty linked to the sensitivity of the GOCCP cloud detection threshold to the atmospheric features (near the cloud detection SR threshold but below, section 2.1 and Table 1, row 7).

disagreements related to definitions of fully attenuated pixel (section 3.3 and Table 1, row 8).

Yet the aircraft flies outside the feature (above $1.5 \mathrm{~km}$ ), measuring only clear sky and finally detects clouds as it gets inside the feature at $77.44^{\circ} \mathrm{N}$. This situation partially explains the other fraction of GOCCP (Table $2 \mathrm{~b}$, Arctic cases, $F_{\text {Aclear/Ccloud: }} 38.5 \%$ and $3.1 \%$ ) and ST (Table $2 \mathrm{~b}$, Arctic cases, $F_{\text {Aclear/Ccloud: }} 43.2 \%$ and $12.8 \%$ ). It also occurs around $77.8^{\circ} \mathrm{N}$ and $78^{\circ} \mathrm{N}$ (blue circles in Figure 3 ) and to a lesser extent in midlatitude cases (Table $2 \mathrm{a}$, midlatitudes, $\left.F_{\text {Aclear/Ccloud }}\right)$. The finer vertical resolution of $\mathrm{KU}$ drastically reduces these disagreements with the in situ retrievals compared to GOCCP and ST, at both midlatitude and Arctic latitude (e.g., Table $2 \mathrm{~b}, F_{\text {Aclear/Ccloud: }} 0.5 \%$ and $0 \%$ ). Finally, the finer vertical resolution also enhances the clear sky detection (Tables $2 \mathrm{a}$ and $2 \mathrm{~b}, F_{\text {Aclear/Cclear }}$ ). For example, between $77.8^{\circ} \mathrm{N}$ and $78^{\circ} \mathrm{N}$ (blue circles in Figure $3 \mathrm{i}$ ), $\mathrm{KU}$ detects clear sky in agreement with the in situ retrievals (black points) whereas GOCCP and ST diagnose clouds all along the track (blue circles in Figures $3 \mathrm{e}$ and $3 \mathrm{~g}$ ).

\subsection{Lidar Attenuation}

In low-level Arctic clouds, the aircraft probe detects clouds that CALIOP does not (Table 2b: $1.4 \%<$ $\left.F_{\text {Acloud/Cclear }}<40.1 \%\right)$. Most of these should be classified as fully attenuated instead of clear sky $\left(F_{\text {Acloud/Catt }}\right)$, particularly in GOCCP $\left(F_{\text {Acloud/Cclear }}=21.8 \%\right.$ and $\left.20.7 \%\right)$ and $\mathrm{KU}\left(F_{\text {Acloud/Cclear }}=40.1 \%\right.$ and $34.9 \%)$. Indeed, as the laser beam penetrates successive particulate layers, eventually, the laser beam gets fully attenuated (when the optical depth of the penetrated layers is higher than about 3). For example, this happens between $77.51^{\circ} \mathrm{N}$ and $77.68^{\circ} \mathrm{N}$ in Figure 3 (left column, yellow circles) and between $78.4^{\circ} \mathrm{N}$ and $78.45^{\circ} \mathrm{N}$ in Figure 3 (right column, yellow circles).

The differences here are a direct consequence of the different definitions of fully attenuated pixels in each algorithm (Table 1): KU classifies the "fully attenuated" pixels as "clear," GOCCP classifies fully attenuated where SR $<0.01$, and ST classifies "fully attenuated" when the laser does not detect the surface echo, depending on the slope of the lidar signal at higher altitudes. Unlike GOCCP and KU, ST diagnoses much more fully attenuated pixels (Table $2 \mathrm{~b}: F_{\text {Acloud/Catt }}=27.8 \%$ and $8.2 \%$ ). The direct consequence is a significant reduction of the clear sky fraction in the annual global statistics (section 5). A better representation of the fully attenuated pixels in GOCCP, KU, and ST than the actual one (Table 1, row 8) would improve the agreement statistics with respect to the aircraft data set.

\section{Cloud Phase Validation}

From pixels diagnosed as cloudy in all data sets, we computed statistics of phase agreement (computations are detailed in Text S2). The results are presented in Table 3a for midlatitudes and Table 3b for the Arctic. As 
Table 3a. Statistics of Cloud Phase Detection (\%) Between CALIPSO Products (GOCCP, ST, and KU) and the Colocated Aircraft Measurements for Three Flights at Midlatitudes ${ }^{a}$

\begin{tabular}{|c|c|c|c|c|c|c|c|c|c|c|}
\hline \multicolumn{10}{|c|}{ Midlatitudes } & \multirow[b]{3}{*}{ Comments } \\
\hline \multirow{2}{*}{$\begin{array}{l}\text { Day } \\
\text { Product }\end{array}$} & \multicolumn{3}{|c|}{$2007 / 5 / 16$} & \multicolumn{3}{|c|}{$2007 / 5 / 25$} & \multicolumn{3}{|c|}{$2007 / 5 / 26$} & \\
\hline & GOCCP & ST & $\mathrm{KU}$ & GOCCP & ST & $\mathrm{KU}$ & GOCCP & ST & $\mathrm{KU}$ & \\
\hline$F_{\text {agree }}^{\prime}(\%)$ & 100 & 100 & 100 & 96.9 & 100 & 94.6 & 97.8 & 100 & 100 & Very good agreement ${ }^{\mathrm{b}}$ \\
\hline$F_{\text {Aliq/Cliq }}^{\prime}$ & 0 & 0 & 0 & 0 & 0 & 0 & 0 & 0 & 0 & \\
\hline$F_{\text {Aice/Cice }}^{\prime}$ & 100 & 100 & 100 & 96.9 & 100 & 94.6 & 97.8 & 100 & 100 & \\
\hline$F_{\text {Amix/Cliq }}^{\prime}$ & 0 & 0 & 0 & 0 & 0 & 0 & 0 & 0 & 0 & \\
\hline$F_{\text {Amix/Cice }}^{\prime}$ & 0 & 0 & 0 & 0 & 0 & 0 & 0 & 0 & 0 & \\
\hline$F_{\text {other }}^{\prime}(\%)$ & 0 & 0 & 0 & 3.1 & 0 & 5.4 & 2.2 & 0 & 0 & \\
\hline$F_{\text {Aliq/Cice }}^{\prime}$ & 0 & 0 & 0 & 0 & 0 & 0 & 0 & 0 & 0 & \\
\hline$F_{\text {Aice/Cliq }}^{\prime}$ & 0 & 0 & 0 & 0 & 0 & 5.4 & 2.2 & 0 & 0 & \\
\hline$F_{\text {Aliq/Cun }}^{\prime}$ & 0 & 0 & 0 & 0 & 0 & 0 & 0 & 0 & 0 & \\
\hline$F_{\text {Aice/Cun }}^{\prime}$ & 0 & 0 & 0 & 3.1 & 0 & 0 & 0 & 0 & 0 & \\
\hline$F_{\text {Amix/Cun }}^{\prime}$ & 0 & 0 & 0 & 0 & 0 & 0 & 0 & 0 & 0 & \\
\hline
\end{tabular}

${ }^{\mathrm{a}} \mathrm{F}_{\text {agr, }}^{\prime} F_{\text {dis, }}^{\prime}$ and $\mathrm{F}_{\text {uncert }}$ correspond to agreement, disagreement, and uncertain fractions. The sum of the three main fractions or the nine subfractions is equal to $100 \%$. Hereafter, the definition of the symbols are used in the table; Days are formatted as year/month/day. Bold data are the main category, while italic data correspond to the subcategory.

${ }^{b}$ All the data sets agree very well with the aircraft cloud phase measurements at midlatitudes, meaning that methods based on polarization are robust to retrieve the ice phase of high midlatitude clouds (section 4.1).

was the case with the cloud detection validation (section 3), results are separated in two main categories. The first five rows of Tables $3 \mathrm{a}$ and $3 \mathrm{~b}$ represent the agreement fraction ( $F_{\text {agree, }}^{\prime}$ the prime distinguishes between cloud and cloud phase determination statistics). It includes clouds diagnosed as ice or liquid by the aircraft and the satellite retrievals $\left(F_{\text {Aice/Cice }}^{\prime}\right.$ and $\left.F_{\text {Aliq/Cliq }}^{\prime}\right)$ as well as clouds diagnosed as being mixed-phase by the aircraft probe and ice or liquid by the satellite retrievals $\left(F_{\text {Amix/Cice }}^{\prime}\right.$ and $\left.F_{\text {Amix/Cliq }}^{\prime}\right)$. The other fraction ( $F_{\text {other, }}^{\prime}$ rows 6-11) corresponds to: the aircraft probe and the satellite retrievals detecting opposite cloud phase $\left(F_{\text {Aliq/Cice }}^{\prime}\right.$ and $\left.F_{\text {Aice/Cliq }}^{\prime}\right)$ and the fraction of undefined-phase pixels $\left(F_{\text {Aliq/Cun }}^{\prime} F_{\text {Aice/Cun, }}^{\prime}\right.$ and $F^{\prime}$ Amix/Cun). The sum of the two categories (and nine subcategories) is 100\%. In section 4.2, we investigated the Arctic cases further because the agreement fraction of the midlatitude cases is almost $100 \%$ (always $>94.6 \%$, section 4.1) and the aircraft probe shows no liquid or mixed-phase clouds contrary to the Arctic cases.

Table 3b. Statistics of Cloud Phase Detection (\%) Between CALIPSO Products (GOCCP, ST, and KU) and the Colocated Aircraft Measurements for Two Flights in the Arctic $^{a}$

\begin{tabular}{|c|c|c|c|c|c|c|c|}
\hline \multicolumn{7}{|c|}{ Arctic } & \multirow[b]{3}{*}{ Comments } \\
\hline \multirow{2}{*}{$\frac{\text { Day }}{\text { Product }}$} & \multicolumn{3}{|c|}{$2007 / 4 / 7$} & \multicolumn{3}{|c|}{$2007 / 4 / 9$} & \\
\hline & GOCCP & ST & $\mathrm{KU}$ & GOCCP & ST & $\mathrm{KU}$ & \\
\hline $\mathbf{F}_{\text {agree }}^{\prime}(\%)$ & 52.2 & 74.7 & 79.8 & 56.1 & 51.5 & 37.5 & \\
\hline$F_{\text {Aliq/Cliq }}^{\prime}$ & 43.9 & 60.2 & 62.4 & 46.9 & 38.8 & 32.5 & \\
\hline$F_{\text {Aice/Cice }}^{\prime}$ & 1.9 & 0 & 0 & 0 & 0 & 0 & \\
\hline$F_{\text {Amix/Cliq }}^{\prime}$ & 6.4 & 14.5 & 17.4 & 9.2 & 6.7 & 2.5 & Clouds with Liquid at the top ${ }^{b}$ \\
\hline$F_{\text {Amix/Cice }}^{\prime}$ & 0 & 0 & 0 & 0 & 6 & 2.5 & \\
\hline $\mathbf{F}_{\text {other }}^{\prime}(\%)$ & 47.8 & 25.3 & 20.2 & 43.9 & 48.5 & 62.5 & \\
\hline$F_{\text {Aliq/Cice }}^{\prime}$ & 0 & 0 & 6.2 & 3.1 & 14 & 56.7 & Noisy measurements ${ }^{c}$ (SNR) \\
\hline$F_{\text {Aice/Cliq }}^{\prime}$ & $5.2(1)$ & $20.4(4.2)$ & $14(3.4)$ & $28.1(11.8)$ & $26.1(10)$ & $5.8(3.3)$ & Attenuation and vertical resolution ${ }^{d}$ Sensitivity to $g$ factor in aircraft \\
\hline$F_{\text {Aliq/Cun }}^{\prime}$ & 17 & 4.9 & 0 & 11.4 & 7.7 & 0 & Undefined phase in BL clouds due to noise in polarization channel ${ }^{f}$ \\
\hline$F_{\text {Aice/Cun }}^{\prime}$ & 17.6 & 0 & 0 & 1.3 & 0 & 0 & \\
\hline$F_{\text {Amix/Cun }}^{\prime}$ & 8 & 0 & 0 & 0 & 0.7 & 0 & \\
\hline
\end{tabular}

${ }^{\mathrm{a}} F_{\text {agr, }}^{\prime} F_{\text {dis, }}^{\prime}$ and $F_{\text {uncert }}^{\prime}$ correspond to agreement, disagreement, and uncertain fractions. The sum of the three main fractions or the nine subfractions is equal to $100 \%$. Hereafter, the definition of the symbols are used in the table; Days are formatted as year/month/day. Bold data are the main category, while italic data correspond to the subcategory.

${ }^{b}$ Mixed-phase clouds are mostly dominated by the liquid phase in CALIPSO products (section 4.2).

'Disagreements linked to the noise on CALIPSO measurements (section 4.2.iii).

${ }^{\mathrm{d}}$ Disagreements are caused by lidar attenuation and vertical resolution (section 4.2.i).

e Disagreements are related to the sensitivity of the aircraft cloud phase to the asymmetry $g$ factor (section 4.2.ii and Table 1, row 13).

fOverrepresentation of undefined-phase pixels because the aircraft flies into boundary layer clouds that are optically thick (SR > 30; section 4.3 and Table 1, last row). 


\subsection{Midlatitudes}

At midlatitudes, the agreement fraction is very high for all CALIPSO data sets (Table $3 a, F_{\text {agr }}^{\prime}>94.6 \%$ ). In these regions, clouds above $8 \mathrm{~km}$ are usually composed of homogeneous layers of ice crystals (cirrus clouds) and scarcely composed of liquid droplets. Furthermore, the aim of the CIRCLE-2 campaign was to document the microphysical properties of cirrus clouds and in situ measurements focused on such clouds. Optically thin clouds, such as cirrus, weakly attenuate the lidar signal and introduce little noise in the measurements, which facilitates the cloud phase identification. The very high agreement fraction shows that methods from the three CALIPSO products based on the polarization (Table 1, rows 12 and 13) all consistently retrieve the proper ice phase of high clouds at midlatitudes.

\subsection{Arctic Clouds}

Agreement fractions between the CALIPSO products and the aircraft measurements are lower in Arctic lowlevel clouds than in midlatitude high-level clouds (Table $3 \mathrm{~b}, F_{\text {agree: }}^{\prime} 37.5 \%$ to $79.8 \%$ ) and mostly come from supercooled liquid clouds. In addition, a substantial part of the agreement fraction is due to clouds classified as being mixed-phase by the airborne PN (Table $3 \mathrm{~b}, F_{\text {Amix/Cice }}^{\prime}$ and $F_{\text {Amix/Cliq }}^{\prime}: 2.5 \%$ to $17.4 \%$ ). In the Arctic, the low-level stratiform clouds are typically composed of a liquid layer on top with precipitating ice particles beneath [e.g., de Boer et al., 2009; Cesana et al., 2012], as in the two Arctic cases under study. In most clouds identified as mixed-phase by the airborne PN, liquid droplets are more numerous and dominate the lidar signal, leading to a liquid phase classification in CALIPSO products. This is consistent with the fact that airborne PN mixed-phase clouds are dominated by the liquid phase and also confirms that the CALIOP lidar is more sensitive to the cloud top phase (here liquid) [e.g., Hu et al., 2010], provided that the signal is not much attenuated by clouds above. The three main sources of the differences between the lidar products and the aircraft measurements are, in order of importance as follows:

i. Attenuation and vertical resolution. The main reason of these differences is the combined effect of the laser beam attenuation and the vertical resolution (Table $3 \mathrm{~b}, F_{\text {Aice/Cliq }}^{\prime}$ ). As mentioned in section 3.3, the nominal resolution of the CALIOP lidar $(30 \mathrm{~m}$ to $60 \mathrm{~m})$ is finer than those of CALIPSO products under study ( $240 \mathrm{~m}$ at best). For ST, the cloud mask and the cloud phase mask are first applied to the full resolution profiles, and then cloud fraction and cloud phase are projected into $480 \mathrm{~m}$ pixels, which can lead to mixed-phase $480 \mathrm{~m}$ pixels (Table 1, row 14). For GOCCP, the cloud phase mask is applied after averaging the signal onto the $480 \mathrm{~m}$ vertical resolution. For $\mathrm{KU}$, a continuity test is applied at the finest vertical resolution so that the most probable phase is determined for the $240 \mathrm{~m}$ pixel. Thus, a cloudy pixel in GOCCP and $\mathrm{KU}$ is never identified as mixed-phase: it may be diagnosed as liquid even if some parts of the pixel contain ice, and vice versa. This explains some differences, where the aircraft flies into the ice part of a pixel with a liquid-dominated signal (Table $3 b, F_{\text {Aice/Cliq }}^{\prime}$ ). Following the same principle, in all CALIPSO data sets, ice/liquid/mixed-phase pixels may contain fully attenuated sublayers. For those partly attenuated pixels, the cloud phase is identified as a function of the nonattenuated part. For example, assume that the aircraft flies into the attenuated portion of the whole CALIPSO pixel. It will lead to a difference if the (aircraft) cloud phase of the attenuated portion is different from the cloud phase of the whole CALIPSO pixel, for example, Figures $3 \mathrm{a}, 3 \mathrm{c}, 3 \mathrm{e}, 3 \mathrm{~g}$, and $3 \mathrm{i}$ around $77.69^{\circ} \mathrm{N}$ (green circles in left column). This is frequent in Arctic stratiform clouds often topped with an optically thick liquid layer, which strongly attenuates the signal and ice layers underneath [e.g., Curry et al., 1996; de Boer et al., 2009]. Another example between $78.37^{\circ} \mathrm{N}$ and $78.40^{\circ} \mathrm{N}$ is shown, and between $960 \mathrm{~m}$ and $1440 \mathrm{~m}$ (Figures $3 \mathrm{~b}, 3 \mathrm{~d}, 3 \mathrm{f}, 3 \mathrm{~h}$, and $3 \mathrm{j}$, right column, see green circles). GOCCP (Figure 3f) and ST (Figure 3h) diagnose liquid clouds whereas the aircraft probe measures ice particles in the lower portion of the $480 \mathrm{~m}$ pixel. In this particular portion, $\mathrm{KU}$ ( Figure 3j), which has a higher vertical resolution of $240 \mathrm{~m}$, diagnoses clear sky. This corresponds actually to fully attenuated layers that do not contribute to the cloud phase classification.

ii. Asymmetry factor. Here we discuss the sensitivity of cloud phase to the asymmetry factor $g$ from PN airborne measurements (section 2.4). When $g$ is right below the 0.8 limit identifying ice (i.e., $0.79<g<0.8$ ), small droplet amounts might be present in the sampled cloud although it is dominated by the ice phase [Jourdan et al., 2010]. This fraction represents up to $11.8 \%$ of the $F_{\text {Aice/Cliq }}^{\prime}$ cases (see footnote (e) compared to total numbers in Table 3b).

iii. Noisy signal. The noise particularly affects the perpendicular signal because of its lower value compared to the parallel signal. Besides, the effect of the noise in the perpendicular channel is shifted in time 
compared to the total ATB, leading to artificially high depolarization ratios ( $\delta$ ) (Figure S2). The noise is essentially induced by solar photons and highly reflective clouds and may be enhanced by upper cloud layer features, which significantly attenuate the signal. As a result, false classification of liquid clouds into ice clouds may arise, for example, around $78.65^{\circ} \mathrm{N}$ between $1 \mathrm{~km}$ and $1.5 \mathrm{~km}$ in Figures $3 \mathrm{~b}, 3 \mathrm{~d}, 3 \mathrm{f}, 3 \mathrm{~h}$, and $3 \mathrm{j}$

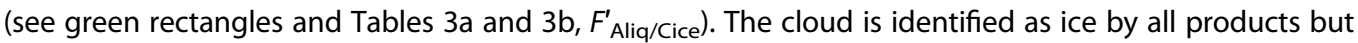
GOCCP (cloud optically too thin to pass the GOCCP cloud detection threshold). We also suspect that around $78.68-78.75^{\circ} \mathrm{N}$, the cloud particle phase becomes ambiguous for all three products due to the high noise in the original data resulting from daylight pollution and highly reflective clouds.

Overall, the differences between the CALIPSO products and the aircraft measurements are mostly related to the vertical dimension (including attenuation and noise). By selecting the aircraft measurements that are well collocated with the nonattenuated signal near the cloud top region in CALIPSO observations (e.g., between 77.44 and 77.47 and between 77.73 and 77.77 for 7 April and between 78.61 and 78.67 for 9 April), we obtain higher agreement fractions in all products (about $70 \%$ and more, not shown). In addition of being able to determine the cloud phase of several vertical layers, the above discussion highlights the ability of CALIOP lidar to retrieve the cloud phase along track (i.e., horizontally) when the signal is not fully attenuated.

\subsection{Mixed-Phase, Undefined-Phase, and Unknown Clouds}

In the two Arctic case studies, respectively, $42.6 \%$ and $12.7 \%$ of GOCCP Arctic clouds are undefined-phase

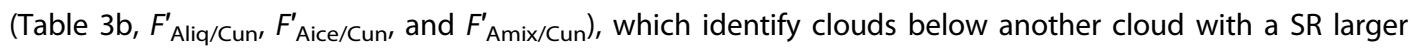
than 30. These are much more frequent in opaque boundary layer liquid clouds in the Arctic (i.e., SR $>30$, Table 1, row 15) than in midlatitude optically thin cirrus. Such a high undefined-phase fraction is not representative of most retrievals: in 3 months of GOCCP data (January-March 2010) we found that 5.3\% of clouds were undefined-phase in the Arctic $\left(60^{\circ} \mathrm{N}\right.$ to $\left.82^{\circ} \mathrm{N}\right)$, much less than in the case studies $(12.7 \%$ and $42.6 \%)$. On a global scale we found $10 \%$ of undefined-phase clouds in GOCCP. The comparison between GOCCP and aircraft data suggests that in the Arctic, undefined-phase clouds occur mostly below liquid clouds and are likely to be mixed-phase clouds. In ST, $F_{\text {Aliq/Cun, }}^{\prime} F_{\text {Aice/Cun, }}^{\prime}$ and $F_{\text {Amix/Cun }}^{\prime}$ fractions (Table $3 b$ ) are mixed-phase clouds (Table 1, row 14). They represent a small part of the cloudy pixels: $4.9 \%$ and $7.7 \%$. In $\mathrm{KU}$, undefined-phase clouds (Table 1, row 15) do not exist in the comparison. In the Arctic, undefined-phase pixels are located in areas of phase transition, between liquid clouds and ice clouds. At midlatitudes, they often are at the cloud base.

\section{Global Scale Comparison of CALIPSO Products}

The previous section compared all CALIPSO data sets using accurate airborne in situ measurements as a reference. Similarity (e.g., robust cloud phase identification of the midlatitude ice clouds by all data sets) and differences (e.g., more false ice clouds by KU and ST compared to GOCCP on 9 April) among the products were observed in these case studies. Unfortunately, the representativeness of this comparison suffers from a lack of available samples. Only five out of nine colocated aircraft flights could be used consistently. We therefore generated 1 year of ice/liquid cloud statistics (from September 2006 to August 2007) for all data sets to get a larger picture of the CALIPSO products comparison.

\subsection{Ice Clouds}

Figure 4 presents the zonal average of ice clouds as reported by the CALIPSO data sets. The global pattern of ice clouds (i.e., fraction of ice clouds $>0$ ) is very similar for GOCCP and KU although ST shows some differences particularly in the tropics at very high level (above $17 \mathrm{~km}$ ) and at midlevel (between 5 and $6.5 \mathrm{~km}$ ). There are also more ice clouds everywhere in ST compared to the two other products. On average, GOCCP exhibits less ice clouds than ST at all heights and latitudes and than KU in high levels (above $8 \mathrm{~km}$ ). The differences between GOCCP and ST (KU) reach 19\% (8\%) in high-level tropical clouds. This significant difference is mostly due to the cloud detection algorithms (Table 1, row 6) rather than cloud phase determination procedures as pointed out by Chepfer et al. [2013]. They reported that by using horizontal averaging up to $80 \mathrm{~km}$ along track and different cloud detection thresholds depending on the nighttime/daytime and height, ST detects more low-signal clouds than GOCCP. Indeed, GOCCP does not use any horizontal averaging and keeps a unique cloud detection threshold for daytime and nighttime data and for all vertical layers. However, by doing so, ST may overestimate the cloud fraction of thin cirrus broken clouds as shown in the 

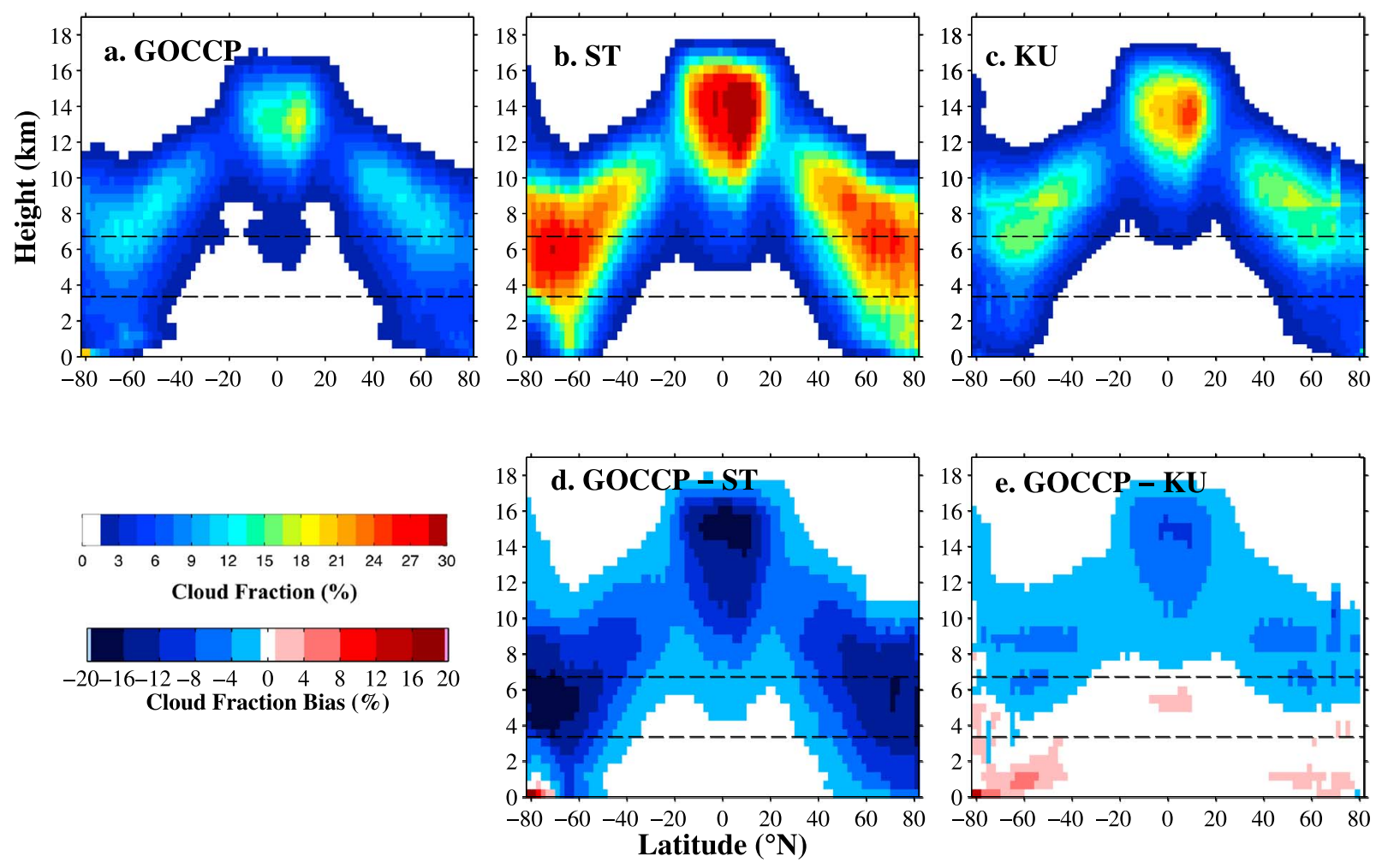

Figure 4. Annual and zonal mean profiles of ice clouds (\%) during September 2006 through August 2007 (nighttime), for a) GOCCP (ice + undefined-phase), b) ST, c) KU. d) difference between GOCCP and ST, and e) differences between GOCCP and KU. The black thin lines correspond to the height that separates low-, middle-, and high-level clouds. 

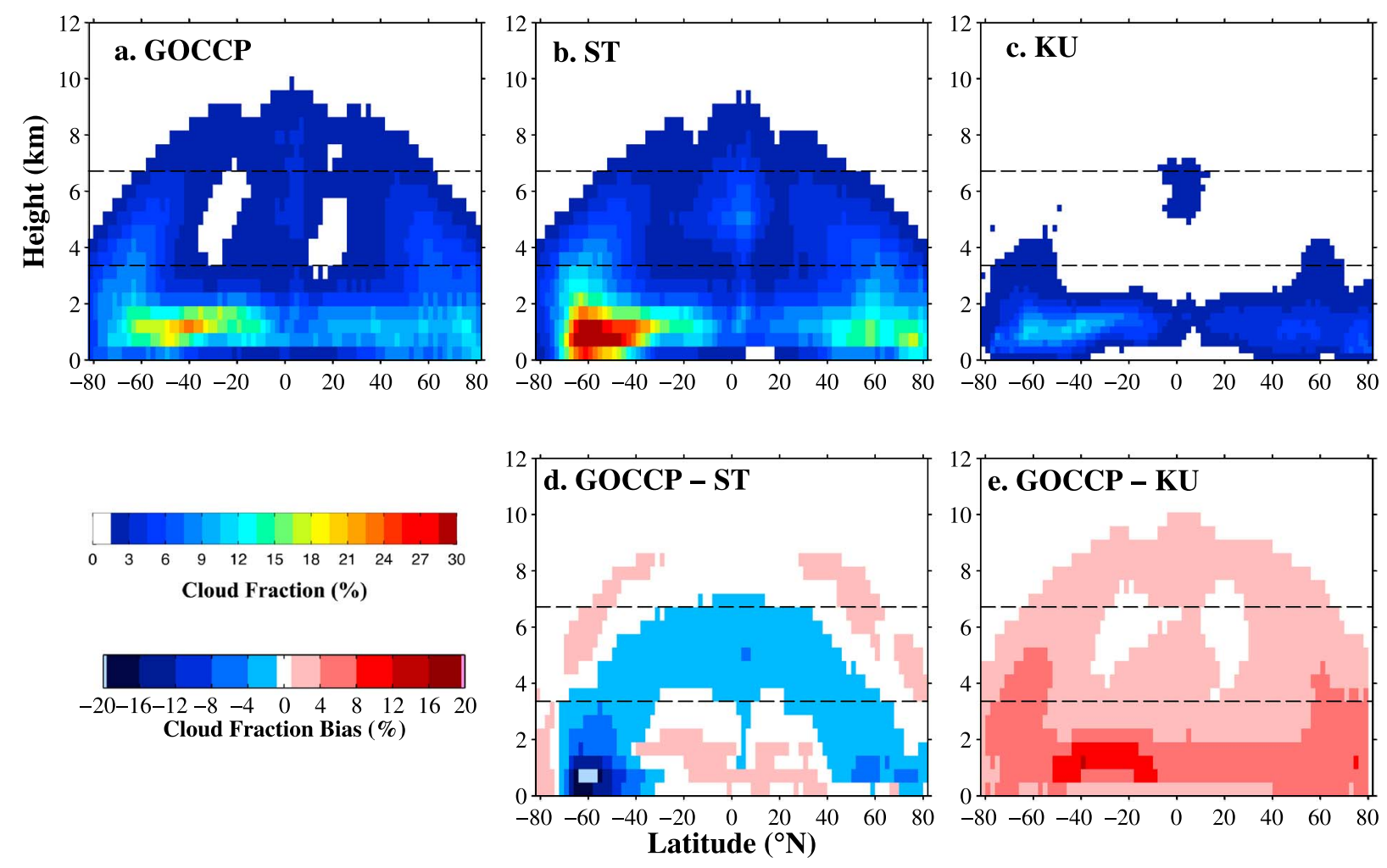

Figure 5. same as Figure 4 for liquid clouds.

The ST and KU liquid fractions remain consistent before and after the tilt change. Another possibility concerns the different treatments of aerosols in the algorithms, which might generate some discrepancies over the dust-polluted regions such as the Saharan desert or the China basin.

\subsection{Cloud Phase Transition Against Temperature}

Previous studies showed that the cloud phase transition between liquid and ice clouds (i.e., the ratio of ice clouds to all clouds, referred as to Phase Ratio, PR) could be represented in a simple way using the temperature [e.g., Bower et al., 1996; Korolev et al., 2003; Hu et al., 2010; Cesana and Chepfer, 2013]. This method lets us easily compare different data sets on the same plot using the same thermodynamical variable-the temperature-as reference. Here we took advantage of the in situ measurements to validate the temperature used in the CALIPSO products (GEOS5-DAS in GOCCP and ST, and European Centre for Medium-Range Weather Forecasts-auxiliary product (ECMWF-AUX) provided by the CloudSat team in KU). We averaged the aircraft temperature onto the CALIPSO horizontal sampling grid and then computed the mean absolute error (MAE) and the maximum error (ME) for all/cloud/clear sky pixels (according to the in situ measurements). The results are presented in Table S1. In the Arctic as well at midlatitudes, the MAE is lower than $2^{\circ} \mathrm{C}$ and the ME no more than $4^{\circ} \mathrm{C}$.

Figure 6 shows the relationship between the PR and the temperature, for the CALIPSO products (GOCCP in red, ST in magenta, and KU in green), the aircraft in situ measurements (black + circle line), and the average between five passive sensor satellites of the Global Energy and Water Cycle Experiment-Cloud Assessment (GEWEX-CA) [Stubenrauch et al., 2013; blue line and blue shade]. To make this figure, we created PhaseTemperature composites by breaking the PR into $3^{\circ}$ temperature bins. For the CALIPSO products, we used the monthly mean files over 1 year (thick dashed lines). As GOCCP and KU relations are sensitive to the change of CALIOP nadir-pointing angle $\left(0.3^{\circ}\right.$ off nadir before 2008 , to $3^{\circ}$ off nadir after), we used the year 2008 to build these relations (ST ice and liquid cloud amount remain consistent before and after the tilt, not shown). The change of nadir angle decreased specular returns of horizontally oriented ice crystals. This resulted in less false cloud detection and less false liquid cloud determination since ice crystal plates produce the same signature as liquid droplets [e.g., Sassen et al., 2012]. In GOCCP, we assumed undefined-phase 


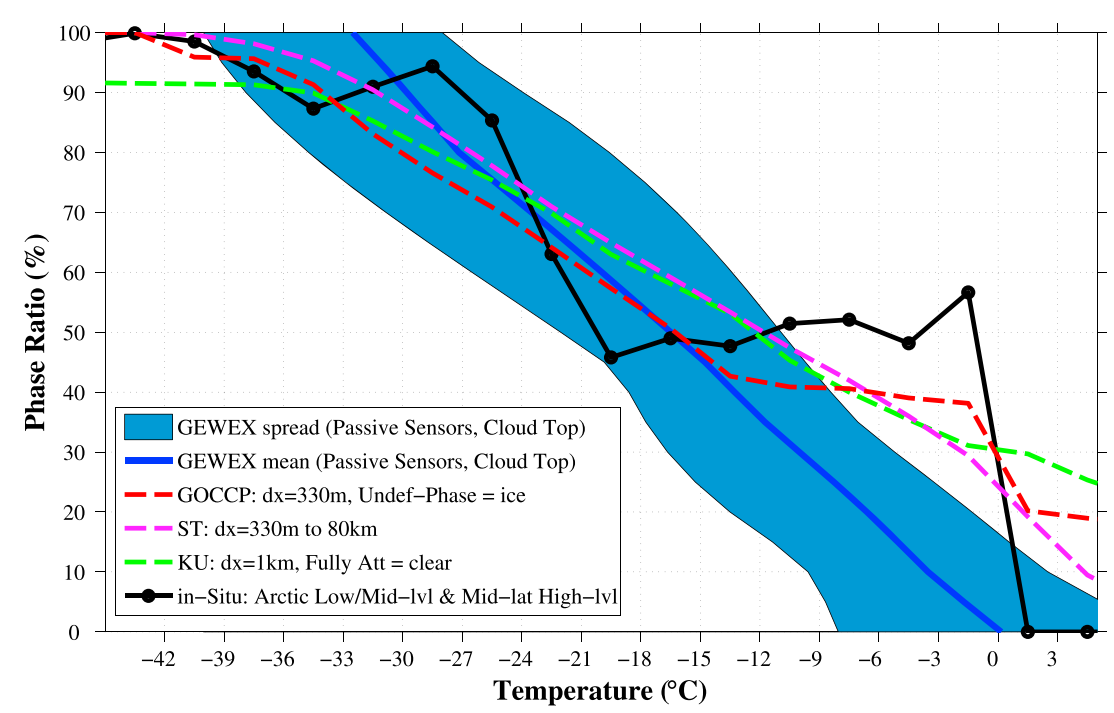

Figure 6. Phase Ratio (\%) as a function of the temperature $\left({ }^{\circ} \mathrm{C}\right)$. Red, green and magenta dashed lines correspond to GOCCP, KU and ST relationships, respectively, using 1 year of monthly data (2008 for GOCCP/KU and September 2006 to August 2007 for ST). The blue line and area are the mean relationship using five passive sensor satellites from the GEWEX-CA experiment and its spread. The black line with circle corresponds to the relation using measurements of nine in situ flights.

clouds-most likely mixed-phase clouds-as dominated by the ice phase. For the airborne PN measurements, we used the nine available flights of the CIRCLE-2 and ASTAR missions. Mixed-phase pixels ( $11 \%$ of the clouds between $-40^{\circ} \mathrm{C}$ and $0^{\circ} \mathrm{C}$ ) are assumed to be liquid as they contain more liquid than ice water [Jourdan et al., 2010]. Finally, for the GEWEX satellite data, we used the phase and temperature of the cloud top cloud covers, included in the monthly mean cloud cover files during the year 2007 (http://climserv.ipsl. polytechnique.fr/gewexca/). Overall, for both the active and passive sensors, this relationship is similar regardless of the year (not shown), consistent with what is shown by Cesana et al. [2015].

In GEWEX-CA satellite observations (five products listed hereafter), cloud phase can be determined by the cloud top temperature (CTT) in the Atmospheric Infrared Sounder-Laboratoire de Météorologie Dynamique product (AIRS-LMD; ice for $C T<-43^{\circ} \mathrm{C}$ ) and the International Satellite Cloud Climatology Project (ISCCP; ice for $\mathrm{CTT}<-13^{\circ} \mathrm{C}$ ). Alternatively, it may also be accomplished by spectral radiance difference in the Moderate Resolution Imaging Spectroradiometer-Science Team product (MODIS-ST) and the Pathfinder Atmosphere Extended climatology (PATMOS-X). Finally, it may be determined by using both spectral radiance and CTT in the MODIS-Clouds and the Earth's Radiant Energy System Science Team product (MODIS-CE). The relation based on in situ measurements highly depends on the type of clouds that were sampled. Consequently, its shape is very different compared to the other data sets: dominated by Arctic cloud cases between $-21^{\circ} \mathrm{C}$ and $0^{\circ} \mathrm{C}$ and by midlatitude cloud cases below $-21^{\circ} \mathrm{C}$. Passive satellites from GEWEX-CA (blue line and shade) exhibit a quasi-linear relation from $0^{\circ} \mathrm{C}$ to $-32.5^{\circ} \mathrm{C}$ with a slightly constant spread of about $12^{\circ} \mathrm{C}$. Due to the lidar ability to detect several cloudy layers and its higher sensitivity to mixed-phase clouds, results from CALIPSO products are different (red/magenta/green dashed lines) from the GEWEX-CA satellites. Also, the shape of the curve is a function of the cloud thresholds, spatial-temporal resolutions, and the cloud phase retrieval methods of the data set, which explains the slight diversity among the CALIPSO products. In addition to that, at temperatures warmer than $-10^{\circ} \mathrm{C}$, disagreements with the airborne PN might be enhanced because CALIPSO does not detect most clouds below the optically thick stratiform layers, which are most likely to be mixed-phase clouds dominated by the ice phase. However, in situ measurements may also misclassify precipitating hydrometeors as cloudy and overestimate the amount of ice with respect to the sum of liquid and ice in these mixed-phase clouds.

We also tested the sensitivity of the cloud phase transition to the type of surface (ocean versus land, Figure 7) for the CALIPSO and GEWEX-CA products, as previous studies showed a variation of the liquid and ice distributions over ocean and land [e.g., Baum et al., 2012]. Regardless of the surface, the PR-temperature relation 


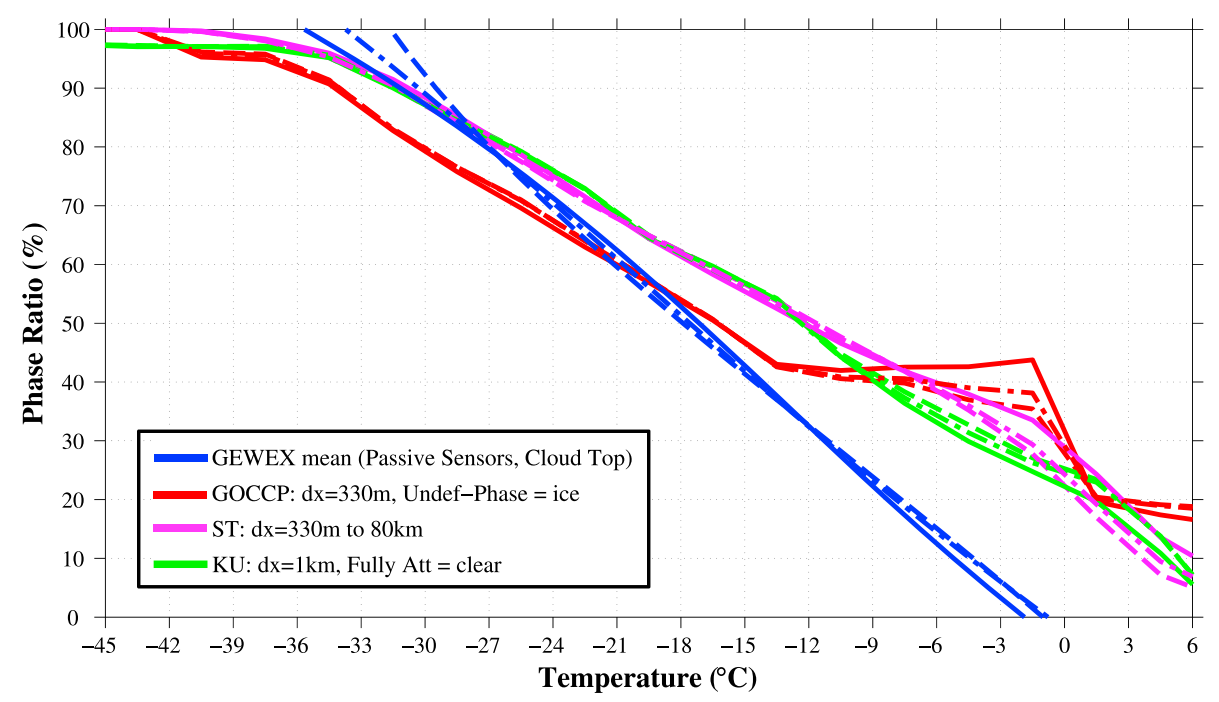

Figure 7. Same as Figure 6 but over ocean (dashed lines), land (solid lines), and both ocean and land (dash dotted).

remains constant (no significant change) in both CALIPSO and GEWEX observations. Yet all CALIPSO products detect more "warm liquid-only" clouds (PR $<10 \%$ and $T>-10^{\circ} \mathrm{C}$ ) over ocean than land, and more "cold iceonly" clouds (PR $>90 \%$ and $T<-30^{\circ} \mathrm{C}$ ) over land whereas the GEWEX-CA observations show significant changes also in the mixed-phase cloud PR range (i.e., $10 \%<\mathrm{PR}<90 \%$; supporting information, Figure S3). The difficulties of the passive satellite to properly retrieve the cloud and cloud phase over land may contribute to this large variation undetected by the CALIPSO products.

While CALIOP retrievals lead to a better representation of the cloud phase compared to passive sensor satellites, the above discussion indicates there is no unique phase-temperature relationship. It depends not only on sensor and algorithmic factors (sampling, cloud detection threshold, resolution, and cloud phase method as shown in this study) but also on environmental variables, such as the humidity, the vertical wind, and the number/type of aerosol particles [e.g., Cesana et al., 2015; Komurcu et al., 2014; Korolev, 2007]. As a consequence, models that have taken into account all these factors/variables in their development show a better agreement with observations than the ones that use temperature-dependent relationship to parameterize the cloud phase [e.g., Cesana et al., 2015].

\section{Conclusion}

Knowing the vertical distribution of clouds and their phase on a global scale is key to understanding and estimating the TOA and surface radiative fluxes in present and future climate. The CALIPSO satellite, thanks to its CALIOP-polarized lidar, lets us document cloud profiles and their thermodynamic phasemostly independent of the temperature-at a high vertical resolution all over the globe during both day and night, even over highly reflective surfaces. It thus provides a unique view of the cloud phase at global scale. Three CALIPSO cloud phase products were evaluated and compared in this paper: the GCM-Oriented CALIPSO Cloud Product, CALIPSO-GOCCP (GOCCP), the CALIPSO Science Team product, CALIPSO-ST (ST), and the CALIPSO Kyushu University product, CALIPSO-KU (KU). These products have been developed by independent teams based on the same Level 1 version 3 CALIPSO data product. Their development has been guided by different scientific questions (section 2). Therefore, differences between the products were expected and need to be evaluated. Here we used airborne in situ measurements colocated in time and space with CALIPSO (section 2.4), from two flights in the Arctic and three flights at midlatitudes, to first validate the cloud detection (section 3). We then validated the cloud phase identification solely using the pixels diagnosed as cloudy by both aircraft and satellite measurements (section 4). Finally, we compared the three satellite data sets in a broader context by using 1 year of global liquid and ice cloud fraction data (section 5 ). 
The results of the comparison with in situ airborne measurements help us better understand the differences among the CALIPSO data sets. Our cloud detection evaluation shows that three main reasons explain differences between the three CALIPSO climatologies:

1. Fully attenuated definition. Our study suggests that the definition of "fully attenuated" pixels have received little attention during the development of the three CALIPSO products, and progresses should be made in the future by all teams to improve it. Indeed, the definition of the "fully attenuated" pixels (Table 1) is different in the three CALIPSO products. In the Arctic, below optically thick clouds, pixels found "cloudy" by the aircraft probe may be declared either "fully attenuated" or "clear sky" in CALIPSO products.

2. Vertical resolution. The atmosphere is not vertically homogeneous at a resolution of $480 \mathrm{~m}$. Thus, the products with the crudest vertical resolution (ST, GOCCP) may mix together clear and cloudy layers stacked within a $480 \mathrm{~m}$ vertical layer and declare it cloudy [e.g., Chepfer et al., 2010, Table 1 versus Table 2]. The aircraft probe samples only a few meters of these $480 \mathrm{~m}$ vertical thick layer, and so in situ measurements cannot be used to validate the vertical resolution of a given CALIOP profile. KU gives results closer to the airborne data (vertical resolution $<1 \mathrm{~m}$ ) than other products, just because its finest vertical resolution $(240 \mathrm{~m})$ documents a cloud volume that is more similar to the one seen by the aircraft probe.

3. Horizontal averaging. When clouds and clear sky alternate at a given altitude along a large portion of the track ( 5 to $80 \mathrm{~km}$ ), the products using along-track averaging can overestimate the cloud amount. This may contribute to overestimate the cloud cover and in turn to a bias in fluxes and Cloud Radiative Effect (CRE). ST horizontally averages the most the lidar profiles before cloud detection and declares cloudy areas that are found clear in the airborne observations (e.g., high cirrus at midlatitudes). As a consequence, ST, which mostly uses 5 to $80 \mathrm{~km}$ horizontal averaging in these high clouds sampled by the aircraft (and may also affect the low-level clouds), diagnoses more "false" clouds (Table 2a, $F_{\text {Aclear/Ccloud: }}$ 10.4\%, 23.6\% and $18.8 \%$ ) than GOCCP (no horizontal averaging; 4.2\%, 2.5\%, and 1.9\%) and $\mathrm{KU}$ (1 $\mathrm{km}$ horizontal averaging below $8.2 \mathrm{~km}$ and none above $8.2 \mathrm{~km} ; 1.7 \%, 0.9 \%$, and $1.8 \%)$.

From the clouds detected by both aircraft and CALIPSO satellite (Tables $2 \mathrm{a}$ and $2 \mathrm{~b}$ : $F_{\text {agree}}$ ), we computed agreement/disagreement fractions regarding the phase detection. Our analysis indicates the following:

1. All CALIPSO products agree very well with the in situ measurements when it comes to detect homogeneous phase of midlatitude ice clouds, meaning that the methods based on the depolarization to identify the ice phase are very robust.

2. Where the cloud phase is not vertically homogeneous within a $480 \mathrm{~m}$ or $240 \mathrm{~m}$ layer, the three products show some disagreements due to the way they take into account these vertical inhomogeneities. These situations mostly occur over the Arctic where mixed-phase cloud layers are ubiquitous in the boundary layer [e.g., Shupe et al., 2011]. According to the in situ airborne measurements in the Arctic (Table 3b,

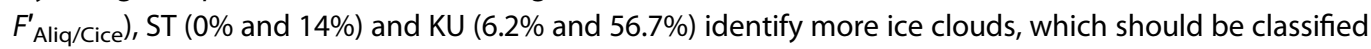
as liquid clouds, than GOCCP ( $0 \%$ and 3.1\%). Although GOCCP has the lowest disagreement fraction with the aircraft, it includes substantial amount of undefined-phase clouds compared to ST and KU. The GOCCP undefined-phase clouds occur mostly below liquid boundary cloud layer, where the polarization signal is too noisy for phase classification. If the aircraft flights considered in this study sampled clouds representative of the general cloud population, then it suggests that the undefined-phase class in GOCCP may be considered as mixed-phase (within a $480 \mathrm{~m}$ vertical layer) most of the time.

3. Some cloudy pixels identified as liquid by all CALIPSO products are measured as ice by the aircraft probe. This confirms that the lidar cloud phase determination is somehow dominated by the cloud top (see also Hu et al. [2010]). Besides, part of them (20\% to 57\%) is near the mixed-phase $g$ value threshold of the PN and thus may contain some liquid droplets, especially because the in situ probe always documents a small vertical extent compared to cloud layer seen by the lidar ( $240 \mathrm{~m}$ or $480 \mathrm{~m}$ ).

4. The phase-temperature relation, often used in GCMs to separate liquid from ice cloud water content, is not unique and may vary as a function of many factors: the vertical and horizontal resolutions at which the clouds are detected, the threshold used to detect clouds, and the definition of the cloud phase. This confirms that for the specific purpose of model evaluation, consistent definitions of the cloud detection and the cloud phase determination need to be used in both observations and models as performed by Cesana and Chepfer [2013] using COSP/lidar and the GOCCP cloud phase product. 
Finally, the global statistics of liquid and ice cloud fraction using 1 year of data are consistent with above findings from orbit/aircraft comparisons. Results highlighted that most differences between the cloud phase of CALIPSO data sets arise from the cloud detection rather than cloud phase restitution when they are compared on a global scale. On one hand, the horizontal averaging of lidar profiles (up to $80 \mathrm{~km}$ in ST) results in significantly higher estimates of ice cloud fraction compared to other CALIPSO products (up to $20 \%$ and $12 \%$ compared to GOCCP and KU in the tropics). On the other hand, the treatment of attenuated pixels mostly affects the liquid fraction in low-level clouds. For example, KU, which assumes the fully attenuated pixels as clear, diagnoses up to $30 \%$ and $24 \%$ less liquid cloud than ST and GOCCP over southern ocean $\left(60^{\circ} \mathrm{S}\right)$.

The results obtained in this study show that detecting mixed-phase clouds and dealing with the lidar attenuation remain challenging. Overcoming these issues may rely on the synergy of multiple instruments on the same satellite mission or on the same constellation, such as the A-train. For example, CloudSat radar (part of the A-train) can detect a solid precipitation signature when the CALIPSO lidar gets attenuated [e.g., Mioche et al., 2015; Zhang et al., 2010]. In that regard, the results obtained here provide a good opportunity to help us prepare and assess the future EarthCARE multiinstrument mission [Illingworth et al., 2015; Reverdy et al., 2015] (launch scheduled for 2018). This satellite will carry a polarized lidar and a radar sensitive to light precipitation that is expected to provide cloud and cloud phase measurements similar to the CALIPSO lidar and thus extend the lidar data set record.

\section{Acknowledgments}

This research was carried out in part at the Jet Propulsion Laboratory, California Institute of Technology, under a contract with the National Aeronautics and Space Administration. H. Okamoto and Y. Hagihara were supported by the Ministry of Education, Culture, Sports, Science and Technology of Japan through a Grant-in-Aid for Scientific Research, Kiban A (25247078) and by the Japan Aerospace Exploration Agency for EarthCARE Research Announcement. CALIPSO-GOCCP observations (orbit and statistics files) were downloaded from the CFMIP-Obs website (http://climserv.ipsl.polytechnique.fr/cfmip-obs/Calipso_goccp.html). CALIPSO-ST and CALIPSO-KU orbit files were provided by the Science Team and Kyushu University Team, respectively, and the statistics files were processed on the CLIMSERV/IPSL computing facility. We would like to thank Bryan Baum, the two anonymous reviewers, and the Editor for their useful comments that improved our manuscript. In particular, we thank the anonymous reviewer who took the time to list and fix grammar and spelling problems in the original manuscript.

\section{References}

Baum, B. A., W. P. Menzel, R. A. Frey, D. Tobin, R. E. Holz, S. A. Ackerman, A. K. Heidinger, and P. Yang (2012), MODIS cloud top property refinements for Collection 6, J. Appl. Meteorol. Climatol., 51, 1145-1163.

Boucher, O., et al. (2013), Clouds and Aerosols, in Climate Change 2013: The Physical Science Basis. Contribution of Working Group I to the Fifth Assessment Report of the Intergovernmental Panel on Climate Change, edited by T. F. Stocker et al., pp. 571-658, Cambridge Univ. Press, Cambridge, U. K., and New York, doi:10.1017/CBO9781107415324.016.

Bower, K. N., S. J. Moss, D. W. Johnson, T. W. Choularton, J. Latham, P. R. A. Brown, A. M. Blyth, and J. Cardwell (1996), A parametrization of the ice water content observed in frontal and convective clouds, Q. J. R. Meteorol. Soc., 122, 1815-1844, doi:10.1002/qj.49712253605.

Cesana, G., and H. Chepfer (2013), Evaluation of the cloud water phase in a climate model using CALIPSO-GOCCP, J. Geophys. Res. Atmos, 118, 7922-7937, doi:10.1002/jgrd.50376.

Cesana, G., J. E. Kay, H. Chepfer, J. M. English, and G. deBoer (2012), Ubiquitous low-level liquid-containing Arctic clouds: New observations and climate model constraints from CALIPSO-GOCCP, Geophys. Res. Lett., 39, L20804, doi:10.1029/2012GL053385.

Cesana, G., D. E. Waliser, X. Jiang, and J.-L. F. Li (2015), Multi-model evaluation of cloud phase transition using satellite and reanalysis data, J. Geophys. Res. Atmos., 120, 7871-7892, doi:10.1002/2014JD022932.

Cheng, A., K.-M. Xu, Y. Hu, and S. Kato (2012), Impact of a cloud thermodynamic phase parameterization based on CALIPSO observations on climate simulation, J. Geophys. Res., 117, D09103, doi:10.1029/2011JD017263.

Chepfer, H., S. Bony, D. M. Winker, M. Chiriaco, J.-L. Dufresne, and G. Seze (2008), Use of CALIPSO lidar observations to evaluate the cloudiness simulated by a climate model, Geophys. Res. Lett., 35, L15704, doi:10.1029/2008GL034207.

Chepfer, H., S. Bony, D. Winker, G. Cesana, J. L. Dufresne, P. Minnis, C. J. Stubenrauch, and S. Zeng (2010), The GCM Oriented Calipso Cloud Product (CALIPSO-GOCCP), J. Geophys. Res., 115, D00H16, doi:10.1029/2009JD012251.

Chepfer, H., G. Cesana, D. Winker, B. Getzewich, M. Vaughan, and Z. Liu (2013), Comparison of two different cloud climatologies derived from CALIOP Level 1 observations: The CALIPSO-ST and the CALIPSO-GOCCP, J. Atmos. Oceanic Technol., doi:10.1175/JTECH-D-12-00057.1.

Curry, J., W. B. Rossow, D. Randall, and J. L. Schramm (1996), Overview of Arctic cloud and radiation characteristics, J. Clim., 9, 1731-1764, doi:10.1175/1520-0442(1996)009<1731:OOACAR>2.0.CO;2.

de Boer, G., E. W. Eloranta, and M. D. Shupe (2009), Arctic Mixed-Phase Stratiform Cloud Properties from Multiple Years of Surface-Based Measurements at Two High-Latitude Locations, J. Atmos. Sci., 66(9), 2874-2887, doi:10.1175/2009JAS3029.1.

Eichler, H., A. Ehrlich, M. Wendisch, G. Mioche, J.-F. Gayet, M. Wirth, C. Emde, and A. Minikin (2009), Influence of ice crystal shape on retrieval of cirrus optical thickness and effective radius: A case study, J. Geophys. Res., 114, D19203, doi:10.1029/2009JD012215.

Engvall, A.-C., R. Krejci, J. Ström, R. Treffeisen, R. Scheele, O. Hermansen, and J. Paatero (2008), Changes in aerosol properties during spring-summer period in the Arctic tropospheric aerosol during late spring and summer, Tellus, 60B(2008), 392-404, doi:10.1111/ j.1600-0889.2008.00348.x.

Forbes, R. M., and M. Ahlgrimm (2014), On the Representation of High-Latitude Boundary Layer Mixed-Phase Cloud in the ECMWF Global Model, Mon. Weather Rev., 142, 3425-3445, doi:10.1175/MWR-D-13-00325.1.

Gayet, J.-F., O. Crépel, J.-F. Fournol, and S. Oshchepkov (1997), A new airborne Polar Nephelometer for the measurements of optical and microphysical cloud properties. Part I: Theoretical design, Ann. Geophys., 15, 451-459, doi:10.1007/s00585-997-0451-1.

Gayet, J.-F., S. Asano, A. Yamazaki, A. Uchiyama, A. Sinyuk, O. Jourdan, and F. Auriol (2002), Two case studies of continental-type water and maritime mixed-phased stratocumuli over the sea. Part I: Microphysical and optical properties, J. Geophys. Res., 107(D21), 4569, doi:10.1029/2001JD001106.

Gayet, J.-F., R. Treffeisen, A. Helbig, J. Bareiss, A. Matsuki, A. Herber, and A. Schwarzenboeck (2009), On the onset of the ice phase in boundary layer Arctic clouds, J. Geophys. Res., 114, D19201, doi:10.1029/2008JD011348.

Gregory, D., and D. Morris (1996), The sensitivity of climate simulations to the specification of mixed-phase clouds, Clim. Dyn., 12, 641-651.

Goloub, P., M. Herman, H. Chepfer, J. Riedi, G. Brogniez, P. Couvert, G. Seze (2000), Cloud thermodynamic phase classification from the POLDER spaceborn instrument, J. Geophys. Res., 105, 14,747-14,759.

Guignard, A., C. J. Stubenrauch, A. J. Baran and R. Armante (2012), Bulk microphysical properties of semi-transparent cirrus from AIRS: A six year global climatology and statistical analysis in synergy with geometrical profiling data from CloudSat-CALIPSO, Atmos. Chem. Phys., 12, 503-525, doi:10.5194/acp-12-503-2012. 
Hagihara, Y., H. Okamoto, and R. Yoshida (2010), Development of a combined CloudSat-CALIPSO cloud mask to show global cloud distribution, J. Geophys. Res., 115, D0OH33, doi:10.1029/2009JD012344.

Hagihara, Y., H. Okamoto, and Z. Luo (2014), Joint analysis of cloud-top heights from CloudSat and CALIPSO: New insights into cloud-top microphysics, J. Geophys. Res. Atmos., 119, 4087-4106, doi:10.1002/2013JD020919.

Harrison, E. F., P. Minnis, B. R. Barkstrom, V. Ramanathan, R. D. Cess, and G. G. Gibson (1990), Seasonal variation of cloud radiative forcing derived from the Earth Radiation Budget Experiment, J. Geophys. Res., 95, 18,687-18,703, doi:10.1029/JD095iD11p18687.

Heidinger, A. K., and M. J. Pavolonis (2009), Gazing at cirrus clouds for 25 years through a split window, part 1: Methodology, J. Appl. Meteorol. Climatol., 48(2009), 1100-1116.

Heidinger, A. K., M. J. Pavolonis, R. E. Holz, B. A. Baum, and S. Berthier (2010), Using CALIPSO to explore the sensitivity to cirrus height in the infrared observations from NPOESS/VIIRS and GOES-R/ABI, J. Geophys. Res., 115, D00H20, doi:10.1029/2009JD012152.

Heymsfield, A. J., and M. R. Hjelmfelt (1984), Processes of hydrometeor development in Oklahoma convective clouds, J. Atmos. Sci., 41 2811-2835.

Hirakata, M., H. Okamoto, Y. Hagihara, T. Hayasaka, and R. Oki (2014), Comparison of Global and Seasonal Characteristics of Cloud Phase and Horizontal Ice Plates Derived from CALIPSO with MODIS and ECMWF, J. Atmos. Oceanic Technol., 31, 2114-2130, doi:10.1175/ JTECH-D-13-00245.1.

Hu, Y., et al. (2009), CALIPSO/CALIOP cloud phase discrimination algorithm, J. Atmos. Oceanic Technol., 26(11), 2293-2309, doi:10.1175/ 2009JTECHA1280.1.

Hu, Y., S. Rodier, K. Xu, W. Sun, J. Huang, B. Lin, P. Zhai, and D. Josset (2010), Occurrence, liquid water content, and fraction of supercooled water clouds from combined CALIOP/IIR/MODIS measurements, J. Geophys. Res., 115, D00H34, doi:10.1029/2009JD012384.

Illingworth, A. J., et al. (2015), The EarthCARE Satellite: The Next Step Forward in Global Measurements of Clouds, Aerosols, Precipitation, and Radiation, Bull. Am. Meteorol. Soc., 96, 1311-1332, doi:10.1175/BAMS-D-12-00227.1.

Jin, H., and S. L. Nasiri (2014), Evaluation of AIRS Cloud-Thermodynamic-Phase Determination with CALIPSO, J. Appl. Meteorol. Climatol., 53, 1012-1027.

Jourdan, O., G. Mioche, T. J. Garrett, A. Schwarzenböck, J. Vidot, Y. Xie, V. Shcherbakov, P. Yang, and J.-F. Gayet (2010), Coupling of the microphysical and optical properties of an Arctic nimbostratus cloud during the ASTAR 2004 experiment: Implications for light-scattering modeling, J. Geophys. Res., 115, D23206, doi:10.1029/2010JD014016.

Kahn, B. H., et al. (2014), The Atmospheric Infrared Sounder version 6 cloud products, Atmos. Chem. Phys., 14, 399-426, doi:10.5194/ acp-14-399-2014.

Kandel, R., M. Viollier, P. Raberanto, J. P. Duvel, L. A. Pakhomov, V. A. Golovko, A. P. Trishchenko, J. Mueller, E. Raschke, and R. R. Stuhlmann (1998), The ScaRaB Earth radiation budget dataset, Bull. Am. Meteorol. Soc., 79, 765-783.

Kay, J. E., C. Wall, V. Yettella, B. Medeiros, C. Hannay, P. Caldwell, and C. Bitz (2016), Global climate impacts of fixing the Southern Ocean shortwave radiation bias in the Community Earth System Model, J. Clim., doi:10.1175/JCLI-D-15-0358.1.

Komurcu, M., T. Storelvmo, I. Tan, U. Lohmann, Y. Yun, J. E. Penner, Y. Wang, X. Liu, and T. Takemura (2014), Intercomparison of the cloud water phase among global climate models, J. Geophys. Res. Atmos., 119, 3372-3400, doi:10.1002/2013JD021119.

Korolev, A. (2007), Limitations of the Wegener-Bergeron-Findeisen Mechanism in the Evolution of Mixed-Phase Clouds, J. Atmos. Sci., 64, 3372-3375, doi:10.1175/JAS4035.1.

Korolev, A. V., G. A. Isaac, S. G. Cober, J. W. Strapp, and J. Hallett (2003), Microphysical characterization of mixed-phase clouds, Q. J. R. Meteorol. Soc., 129, 39-65, doi:10.1256/qj.01.204.

Li, Z.-X., and H. Le Treut (1992), Cloud-radiation feedbacks in a general circulation model and their dependence on cloud modelling assumptions, Clim. Dyn., 7, 133-139.

Martins, E., V. Noel, and H. Chepfer (2011), Properties of cirrus and subvisible cirrus from nighttime Cloud-Aerosol Lidar with Orthogonal Polarization (CALIOP), related to atmospheric dynamics and water vapor, J. Geophys. Res., 116, D02208, doi:10.1029/2010JD014519.

Mioche, G., D. Josset, J.-F. Gayet, J. Pelon, A. Garnier, A. Minikin, and A. Schwarzenboeck (2010), Validation of the CALIPSO-CALIOP extinction coefficients from in situ observations in midlatitude cirrus clouds during the CIRCLE-2 experiment, J. Geophys. Res., 115, D00H25, doi:10.1029/2009JD012376.

Mioche, G., O. Jourdan, M. Ceccaldi, and J. Delanoë (2015), Variability of mixed-phase clouds in the Arctic with a focus on the Svalbard region: A study based on spaceborne active remote sensing, Atmos. Chem. Phys., 15, 2445-2461, doi:10.5194/acp-15-2445-2015.

Nasiri, S. L., and B. H. Kahn (2008), Limitations of Bispectral Infrared Cloud Phase Determination and Potential for Improvement, J. Appl. Meteorol. Climatol., 47, 2895-2910, doi:10.1175/2008JAMC1879.1.

Naud, C. M., A. D. Del Genio, M. Haeffelin, Y. Morille, V. Noel, J.-C. Dupont, D. D. Turner, C. Lo, and J. Comstock (2010), Thermodynamic phase profiles of optically thin midlatitude clouds and their relation to temperature, J. Geophys. Res., 115, D11202, doi:10.1029/2009JD012889.

Noel, V., and H. Chepfer (2010), A global view of horizontally oriented crystals in clouds from CALIPSO, J. Geophys. Res., D00H23, doi:10.1029/ 2009JD012365

Noel, V., H. Chepfer, M. Haeffelin, and Y. Morille (2006), Classification of Ice Crystal Shapes in Midlatitude Ice Clouds from Three Years of Lidar Observations over the SIRTA Observatory, J. Atmos. Sci., 63, 2978-2991, doi:10.1175/JAS3767.1.

Noel, V., A. Hertzog, H. Chepfer, and D. Winker (2008), Polar Stratospheric Clouds over Antarctica from the CALIPSO Spaceborne Lidar, J. Geophys. Res., 113, D02205, doi:10.1029/2007JD008616.

Ohmura, A., et al. (1998), Baseline Surface Radiation Network (BSRN/WCRP): New precision radiometry for climate research, Bull. Am. Meteorol. Soc., 79, 2115-2136.

Okamoto, H., et al. (2007), Vertical cloud structure observed from shipborne radar and lidar: Mid-latitude case study during the MR01/K02 cruise of the R/V Mirai, J. Geophys. Res., 112, D08216, doi:10.1029/2006JD007628.

Okamoto, H., T. Nishizawa, T. Takemura, K. Sato, H. Kumagai, Y. Ohno, N. Sugimoto, A. Shimizu, I. Matsui, and T. Nakajima (2008), Vertical cloud properties in the tropical western Pacific Ocean: Validation of the CCSR/NIES/FRCGC GCM by shipborne radar and lidar, J. Geophys. Res., 113, D24213, doi:10.1029/2008JD009812.

Okamoto, H., K. Sato, and Y. Hagihara (2010), Global analysis of ice microphysics from CloudSat and CALIPSO: Incorporation of specular reflection in lidar signals, J. Geophys. Res., 115, D22209, doi:10.1029/2009JD013383.

Parol, F., J. Buriez, G. Brogniez, and Y. Fouquart (1991), Information Content of AVHRR channels 4 and 5 with respect to the effective radius of cirrus cloud particles, J. Appl. Meteorol., 30, 973-984.

Pavolonis, M. J. (2010), Advances in extracting cloud composition information from spaceborne infrared radiances-A robust alternative to brightness temperatures, part 1: Theory, J. Appl. Meteorol. Climatol., 49, 1992-2012.

Pavolonis, M. J., and J. R. Key (2003), AntArctic Cloud Radiative Forcing at the Surface Estimated from the AVHRR Polar Pathfinder and ISCCP D1 Datasets, 1985-93, J. Appl. Meteorol., 42, 827-840, doi:10.1175/1520-0450(2003)042<0827:ACRFAT>2.0.CO;2. 
Pavolonis, M. J., A. K. Heidinger, and T. Uttal (2005), Daytime Global Cloud Typing from AVHRR and VIIRS: Algorithm Description, Validation, and Comparisons, J. Appl. Meteorol., 44, 804-826, doi:10.1175/JAM2236.1.

Pitts, M. C., L. R. Poole, A. Dörnbrack, and L. W. Thomason (2011), The 2009-2010 Arctic polar stratospheric cloud season: A CALIPSO perspective, Atmos. Chem. Phys., 11, 2161-2177, doi:10.5194/acp-11-2161-2011.

Platnick, S., M. D. King, S. A. Ackerman, W. P. Menzel, B. A. Baum, J. C. Riedi, and R. A. Frey (2003), The MODIS cloud products: Algorithms and examples from Terra, IEEE Trans. Geosci. Remote Sens., 41(2), 459-473, doi:10.1109/TGRS.2002.808301.

Protat, A., S. A. Young, S. A. McFarlane, T. L’Ecuyer, G. G. Mace, J. M. Comstock, C. N. Long, E. Berry, and J. Delanoë (2014), Reconciling Ground-Based and Space-Based Estimates of the Frequency of Occurrence and Radiative Effect of Clouds around Darwin, Australia, J. Appl. Meteorol. Climatol., 53, 456-478, doi:10.1175/JAMC-D-13-072.1.

Reverdy, M., H. Chepfer, D. Donovan, V. Noel, G. Cesana, C. Hoareau, M. Chiriaco, and S. Bastin (2015), An EarthCARE/ATLID simulator to evaluate cloud description in climate models, J. Geophys. Res. Atmos., 120, 11,090-11,113, doi:10.1002/2015JD023919.

Rienecker, M., et al. (2008), The GEOS-5 Data Assimilation System-Documentation of Versions 5.0.1, 5.1.0, and 5.2.0., vol. 27 of Tech. 20 Rep. Ser. on Global Modeling and Data Assimilation, NASA Goddard Space Flight Center, Greenbelt, MD.

Rienecker, M. M., M. J. Suarez, R. Gelaro R. Todling, J. Bacmeister, E. Liu, M. G. Bosilovich, S. D. Schubert, L. Takacs, and G.-K. Kim (2011), MERRA: NASA's modern-era retrospective analysis for research and applications, J. Clim., 24, 3624-3648.

Rogers, R. R., and M. K. Yau (1989), A Short Course in Cloud Physics, 3rd ed., Butterworth-Heinemann, Burlington.

Rossow, W. B., and R. A. Schiffer (1999), Advances in understanding clouds from ISCCP, Bull. Am. Meteorol. Soc., 80, 2261-2288, doi:10.1175/ 1520-0477(1999)080<2261:AIUCFI>2.0.CO;2.

Rossow, W. B., R. A. Schiffer, P.-J. Lu, and A. Walker (1991), International Satellite Cloud Climatology Project (ISCCP) documentation of cloud data. WMO/TD 266 (revised), World Climate Research Programme (ICSU and WMO), 76 pp.

Sassen, K., V. K. Kayetha, and J. Zhu (2012), Ice cloud depolarization for nadir and off-nadir CALIPSO measurements, Geophys. Res. Lett., 39, L20805, doi:10.1029/2012GL053116.

Sato, K., and H. Okamoto (2011), Refinement of global ice microphysics using spaceborne active sensors, J. Geophys. Res., 116, D20202, doi:10.1029/2011JD01588.

Schotland, R. M., K. Sassen, and R. Stone (1971), Observations by Lidar of Linear Depolarization Ratios for Hydrometeors, J. Appl. Meteorol., 10, 1011-1017, doi:10.1175/1520-0450(1971)010<1011:OBLOLD>2.0.CO;2.

Shupe, M. D. (2011), Clouds at Arctic Atmospheric Observatories, Part II:Thermodynamic phase characteristics, J. Appl. Meteorol. Climatol., 50, 645-661, doi:10.1175/2010JAMC2468.1.

Stephens, G. L., and C. D. Kummerow (2007), The remote sensing of clouds and precipitation from space: A review, J. Atmos. Sci., 64, 3742-3765, doi:10.1175/2006JAS2375.1.

Stephens, G. L., et al. (2002), The CloudSat Mission and the A-Train, Bull. Am. Meteorol. Soc., 83, 1771-1790.

Stephens, G. L., J. Li, M. Wild, C. A. Clayson, N. Loeb, S. Kato, T. L'Ecuyer, P. W. Stackhouse Jr., and T. Andrews (2012), An update on Earth's energy balance in light of the latest global observations, Nat. Geosci., 5, 691-696.

Stubenrauch, C. J., et al. (2013), Assessment of Global Cloud Datasets from Satellites: Project and Database Initiated by the GEWEX Radiation Panel, Bull. Am. Meteorol. Soc., 94, 1031-1049, doi:10.1175/BAMS-D-12-00117.1.

Uppala, S. M., et al. (2005), The ERA-40 re-analysis, Q. J. R. Meteorol. Soc., 131, 2961-3012, doi:10.1256/qj.04.176.

Vaughan, M., K. Powell, R. Kuehn, S. Young, D. Winker, C. Hostetler, W. Hunt, Z. Liu, M. McGill, and B. Getzewich (2009), Fully Automated Detection of Cloud and Aerosol Layers in the CALIPSO Lidar Measurements, J. Atmos. Oceanic Technol., 26, 2034-2050, doi:10.1175/ 2009JTECHA1228.1.

Wielicki, B. A., et al. (1996), Clouds and the Earth's Radiant Energy System (CERES): An earth observing system experiment, Bull. Am. Meteorol. Soc., $77,853-868$.

Winker, D. M., et al. (2010), The CALIPSO Mission: A Global 3D View of Aerosols and Clouds, Bull. Am. Meteorol. Soc., 91, 1211-1229, doi:10.1175/2010BAMS3009.1.

Yoshida, R., H. Okamoto, Y. Hagihara, and H. Ishimoto (2010), Global analysis of cloud phase and ice crystal orientation from Cloud-Aerosol Lidar and Infrared Pathfinder Satellite Observation (CALIPSO) data using attenuated backscattering and depolarization ratio, J. Geophys. Res., 115, D00H32, doi:10.1029/2009JD012334.

Yun, Y., and J. E. Penner (2012), Global model comparison of heterogeneous ice nucleation parameterizations in mixed phase clouds, J. Geophys. Res., 117, D07203, doi:10.1029/2011JD016506.

Zhang, D., Z. Wang, and D. Liu (2010), A global view of midlevel liquid-layer topped stratiform cloud distribution and phase partition from CALIPSO and CloudSat measurements, J. Geophys. Res., 115, D00H13, doi:10.1029/2009JD012143. 